\title{
WORKING
}

paper

\section{Climate-related Risks and Central Banks' Collateral Policy: a Methodological Experiment}

\author{
Antoine Oustry ${ }^{1}$, Bünyamin Erkan ${ }^{2}$, Romain \\ Svartzman ${ }^{3}$ and Pierre-François Weber ${ }^{4}$
}

\author{
December 2020, WP \#790
}

\begin{abstract}
Central banks increasingly acknowledge that climate change is a source of financial risks, which is likely to also impact their conduct of monetary policy. Against this backdrop, the aim of this paper is to explore one potential approach to factoring climate-related transition risks into a central bank's collateral framework. Given the radical uncertainty associated with measuring such risks, this approach relies on so-called climate "alignment" methodologies, which enable to assess the consistency of eligible and pledged marketable assets with specific climate targets. Moreover, this paper proposes a "climate-hedging portfolio approach": instead of seeking to "align" the collateral on an asset-by-asset basis, central banks could aim for "alignment", in aggregate, of the collateral pools pledged by their counterparties with a given climate target. The rationale for this choice is that assessing climate-related risk at the pool level avoids the Eurosystem having to decide on which assets/issuers in the pools should be excluded or capped, and is therefore more compatible with a market neutrality approach. The numerical experiment using Eurosystem marketable criteria data suggests that, in aggregate, neither the Eurosystem eligible collateral universe nor the collateral pledged is "aligned" with the climate targets of the European Union. From this perspective, the Eurosystem marketable collateral can be considered to be exposed to climate-related transition risks. We discuss the potential practical implications of aiming to "align" collateral pools, and suggest avenues for further work.
\end{abstract}

Keywords: Monetary policy; Collateral framework; Climate change; Risk and uncertainty; Eurosystem.

JEL classification: D81, E52, E58, G32, Q51, Q54

The views expressed in this paper are those of the authors and should not be interpreted as reflecting the views of Banque de France, the Eurosystem, or the ENPC. This document is available on publications.banque-france.fr/en

\footnotetext{
${ }^{1}$ Ecole Nationale des Ponts et Chaussées (ENPC), antoine.oustry@enpc.fr

2 Banque de France, bunyamin.erkan@banque-france.fr

3 Banque de France, romain.svartzman@banque-france.fr

${ }^{4}$ Banque de France, pierre-francois.weber@banque-france.fr
} 


\section{NON-TECHNICAL SUMMARY}

Central banks increasingly acknowledge that climate change is a source of financial risks, which will also impact their conduct of monetary policy. Against this backdrop, the aim of this paper is to explore one potential approach to factoring climate-related transition risks into a central bank's collateral framework. Given the radical uncertainty associated with measuring such risks, the methodology explored in this paper relies on so-called climate "alignment" methodologies, which enable us to assess the consistency of eligible and pledged marketable assets with specific climate targets. While such methodologies yield non-financial metrics that do not strictly measure climate-related risks and are also subject to uncertain assumptions, this paper considers that they can be used by a central bank as a relevant gauge of transition risks when managing its collateral framework.

Moreover, this paper proposes a "climate-hedging portfolio approach": instead of seeking to "align" the collateral on an asset-by-asset basis, central banks could aim for "alignment", in aggregate, of the collateral pools pledged by their counterparties with a given climate target. The rationale for this choice is that assessing climate-related risk at the pool level avoids the central bank having to decide on which assets/issuers in the pools should be excluded or capped, and is therefore more compatible with a market neutral approach.

The numerical experiment using Eurosystem marketable collateral data suggests that, in aggregate and despite some differences across methodologies and metrics, neither the Eurosystem eligible collateral universe nor the collateral pledged is "aligned" with the climate targets of the European Union. Hence, the Eurosystem marketable collateral can be considered to be exposed to climate-related transition risks.

However, more work will be needed to account for potential unintended aggregate effects or determined impacts on counterparties in specific countries. More work is also needed to test current results through additional "alignment" methodologies and metrics, and to better capture the "alignment" of asset classes that were not covered properly by this study ${ }^{5}$.

\footnotetext{
${ }^{5}$ We are very grateful to Francesco Papadia for detailed comments and discussion of a previous version of the paper. We also thank participants to Banque de France internal seminar and participants to Bruegel's internal research seminar. Vincent Bignon, Jean Boissinot, Régis Breton, Béatrice Brueckner, Michel Cardona, Gilbert Cette, Stéphane Dees, Vincent Grossmann-Wirth, Anuschka Hilke, Pauline Lez, Scott Oldale, Julie Raynaud and Peter Tankov provided us very valuable contributions and comments. We are thankful to Carbon4 Finance and S\&P Trucost for useful discussions on their methodologies. Potential errors are our own.
} 
Coverage rate and overall climate "alignment" of the pools of collateral pledged by counterparties, based on Carbon4 Finance (left-hand chart) and S\&P Trucost (right-hand chart) methodologies
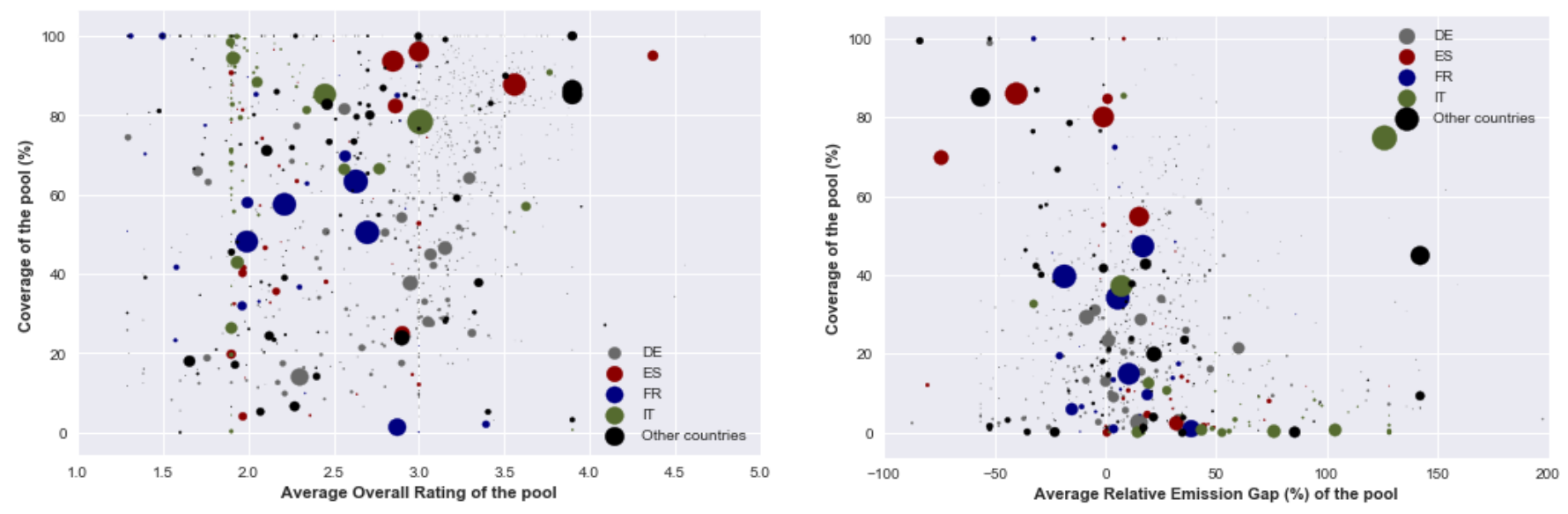

Note: In both charts, the closer a circle is to the y-axis, the more climate "aligned" it is (i.e. the less exposed it is to climate-related transition risks, for the purpose of the study). The size of the circles is proportional to the size of the pool of collateral pledged by each counterparty (classified by country).

Sources: Carbon4Finance, S\&P Trucost, Eurosystem. Authors’ calculations.

\section{Risques climatiques et politique de collatéral des banques centrales : une expérience méthodologique}

\section{RÉSUMÉ}

Les banques centrales reconnaissent de plus en plus que le changement climatique est une source de risques financiers et qu'il pourrait affecter la transmission et la mise en œuvre de la politique monétaire. Dans ce contexte, cet article explore une approche permettant d'intégrer les risques climatiques dans la politique de collatéral d'une banque centrale. Cette approche se base sur des méthodologies dites d' « alignement » climatique, qui permettent d'estimer la cohérence des actifs éligibles et mobilisés dans le cadre du collatéral avec des objectifs climatiques. Plutôt que de chercher à évaluer l' « alignement» de chaque actif, les banques centrales pourraient chercher à ce que les pools de collatéral mobilisés par chaque contrepartie soient compatibles avec des objectifs climatiques, cette approche étant plus compatible avec le principe de neutralité de marché. Notre analyse montre que, en agrégé, le collatéral négociable éligible et mobilisé dans le cadre de l'Eurosystème n'est probablement pas «aligné » avec les objectifs climatiques de l'UE, ce qui suggère qu'il est exposé aux risques de transition. Nous présentons quelques implications pratiques de nos résultats et suggérons des pistes pour de futures études.

Mots-clés : politique monétaire; politique de collatéral; changement climatique; risque et incertitude ; Eurosystème.

Les Documents de travail reflètent les idées personnelles de leurs auteurs et n'expriment pas nécessairement la position de la Banque de France. Ils sont disponibles sur publications.banque-france.fr 


\section{INTRODUCTION}

Central banks and financial supervisors increasingly acknowledge that climate change is a source of financial risks (Carney, 2015; NGFS, 2019a). They acknowledge that it falls within their mandate "to ensure the financial system is resilient to these risks" (NGFS, 2018, 3). So far, most of the efforts carried out by central banks have focused on integrating climate-related risks into prudential supervision (NGFS, 2019a).

Yet, recently, central banks have also intensified their efforts to better understand the implications climate change may have for the conduct of monetary policy, including its "policy space", monetary transmission channels in light of climate change and the design of their policy framework (Coeuré 2018; NGFS, 2020a). In particular, climate change is a prominent topic of the Eurosystem's Strategy Review, which is expected to be concluded by mid-2021. In parallel, several contributors have argued that central banks should "green" their operations (e.g. Dikau, Robins and Volz, 2020; Jourdan and Kalinowski, 2019; Monnin, 2018; Schoenmaker, 2019; van 't Klooster and van Tilburg, 2020). For instance, Dikau, Robins and Volz (2020) argue that central banks' collateral frameworks should exclude assets and/or apply specific haircuts to firms that are vulnerable to climate-related risks.

Against this backdrop, the aim of this paper is to explore one potential approach to factoring climaterelated risks into a central bank's collateral framework. It focuses on transition risks, i.e. those risks associated with a rapid and potentially disorderly transition to a low-carbon economy (NGFS, 2019a). While the practical experiment below applies to the Eurosystem, most of the analysis is intended to be general enough to be relevant beyond the euro area.

This paper thus starts from three premises. First, central banks, like any financial institutions, take on risks on their balance sheet when conducting monetary policy. They protect themselves against these risks through a range of risk protection or control measures, their collateral policy being one of the most prominent. Second, climate change, as mentioned above, is recognised to be a source of financial risks for financial institutions. This implies that central banks, at a minimum, need to assess the extent to which they are exposed to climate-related risks when they implement monetary policy operations. Third, central banks, as monetary authorities implementing a major economic policy, operate under constraints that are distinct from private, commercial financial institutions. These constraints are typically enshrined in a formal, legally binding remit, supplemented by a derived set of operational rules. 
The contribution seeks to take into account several considerations that are pivotal for a central bank. Climate-related risks are distinct from the risks central banks usually measure, control and manage. Indeed, an important feature of climate change is that it is characterised by a deep or radical level of uncertainty (Bolton et al., 2020a; NGFS, 2019b). The so-called physical and transition risks of climate change depend on multiple and interacting dynamics that can lead to nonlinear and cascading effects, potentially translating into extreme values (Weitzman, 2011) and/or systemic impacts (Carney, 2015). Traditional approaches to financial risks are unlikely to be able to handle the complexity and uncertainty associated with climate-related risks, not least because they are backward looking and rest on standard probability laws (Dépoues et al., 2019).

This suggests that managing climate-related risks may entail considering and assessing tools that are not currently mainstream. ${ }^{3}$ Besides, it also implies that it is in a central bank's interest to favour comparatively "simple" tools in order to avoid excessive uncertainty around risk measures.

In this context, approaches developed by the financial industry and various stakeholders to measure and assess climate-related exposures may provide a source of inspiration for central banks (see NGFS, 2020b). One of these approaches consists in so-called climate "alignment" methodologies, which aim to measure the consistency of a portfolio of financial assets with specific climate targets - e.g. a maximum $1.5^{\circ} \mathrm{C}$ or $2^{\circ} \mathrm{C}$ of global warming (Blood and Levina, 2020; Raynaud et al., 2020). While such methodologies do not strictly measure climate-related risks, this paper considers that they can be used by a central bank as a relevant gauge of transition risks when managing its collateral framework. This assessment does not necessarily apply for other institutions (e.g. private financial institutions) and for other activities carried out by central banks, such as financial supervision practices and outright purchases ${ }^{4}$.

This consideration stems from three reasons. First, these methodologies tend to rely on two critical steps (an externally developed energy scenario and an internally designed method to reconcile the scenarios with different entities' current emissions and medium-term strategies) that remain relatively simple to understand, and on assumptions that are relatively transparent and possible to challenge if needed. This avoids being hindered by the radical uncertainty related to measuring climate-related risks as a financial loss.

Second, while these methodologies provide metrics that are not financial by nature (i.e. a measure of (in)consistency with a temperature or other climate target), this is not a problem in the case of a central bank's collateral framework. Unlike private financial institutions, central banks do not simply seek to balance risk and

\footnotetext{
${ }^{3}$ This also applies to integrating climate-related risks into macroprudential regulation. On that front, central banks are using scenario analysis and have strongly leaned towards designing climate stress tests (e.g. Allen et al., 2020; Vermeulen et al., 2019).

${ }^{4}$ Indeed, each institution and each tool face their own challenges and requirements. For instance, an important advantage of the approach described in this paper, that of not intervening directly in the market, could not apply in the case of outright purchases (which by definition entail a direct intervention from central banks).
} 
return considerations, but rather seek to define a relevant risk frontier within which they can transmit monetary policy without taking on undue risk on their balance sheet. In this context, a measure of "alignment" of the assets they accept as collateral is a relevant indicator of how exposed they are to transition risks. ${ }^{5}$

Third, central banks can reduce uncertainty related to the measure of climate-related risks by relying on what we call a "climate-hedging portfolio approach": instead of seeking to assess "alignment" on an assetby-asset basis, central banks could aim for "alignment", in aggregate, of the collateral pools pledged by their counterparties with a given "climate" target (depending on the risk tolerance of the central bank) and their broad resilience to transition risks. This being said, the analysis below remains exploratory and calls for additional studies, including comparisons with other approaches to climate-related risk based on an asset-byasset valuation.

An important side benefit of this approach is that it avoids the risk that the central bank is seen as interfering with market neutrality or political decisions, given that the composition of the collateral pools would remain in the hands of the counterparties.

The intuition behind this reasoning is that it is relevant to consider potential solutions for factoring climate-related risks without prejudice to the different interpretations of central banks' remit as defined by law or a treaty. While discussions about the possibilities allowed by each central bank's remit remain relevant, they are beyond the scope of this paper, which adopts a methodological and operational perspective. In other words, the analysis below takes as given the existing operational principles guiding the implementation of monetary policy, and seeks only to assess certain practical challenges associated with factoring in climaterelated risks.

The paper is structured as follows. Section 2 summarises the literature on climate-related risks and provides the rationale for factoring such risks into a central bank's collateral framework. Section 3 discusses the methodological challenges of doing so, and explains the approach adopted in this paper: the "climatehedging portfolio approach" based on three metrics provided by two providers of climate "alignment" methodologies. Section 4 applies these methodologies and criteria to part of the Eurosystem's eligible and pledged collateral and provides stylised facts on the climate "misalignment" of the collateral. Section 5 discusses the results and some potential technical and policy implications of aiming to "align" the collateral with strict climate targets. Section 6 concludes.

\footnotetext{
${ }^{5} \mathrm{An}$ analogy can be provided through the measurement of systemic risks by the Basel Committee on Banking Supervision (BIS, 2013): the number of jurisdictions in which a bank has activities is not a financial risk metric per se, yet is deemed relevant by financial regulators as one indicator of the degree of systemic risk posed by the institution.
} 


\section{RATIONALE AND CHALLENGES OF INTEGRATING CLIMATE-RELATED RISKS INTO CENTRAL BANKS' COLLATERAL POLICY}

\section{a. CHALLENGES IN EVALUATING CLIMATE-RELATED RISKS}

\section{An overview of climate-related risks}

The central banking community increasingly acknowledges that climate change poses potentially systemic threats to financial stability (Carney, 2015; NGFS, 2018, 2019). Two main types of risks are usually identified. First, physical risks refer to the financial losses that could result from the increase in frequency and severity of climate-related weather events (such as storms and floods) and the effects of long-term changes in climate patterns (such as ocean acidification and rising sea level). For instance, losses related to natural catastrophes have already been increasing over the past decades, and the majority of these losses is not ensured (IAIS, 2018). The worst impacts of climate change are nevertheless likely to lie ahead of us (Lenton et al., 2019; Ripple et al., 2020) and could lead to catastrophic economic and financial outcomes (Weitzman, 2011, 2015).

Second, transition risks relate to the financial impacts that could result from a rapid low-carbon transition, including policy changes, technological breakthroughs or limitations, and shifts in individual preferences or social norms. In particular, if we are to meet ambitious climate targets (e.g. a maximum of $1.5^{\circ} \mathrm{C}$ or $2^{\circ} \mathrm{C}$ of global warming), a large fraction of proven reserves of fossil fuels cannot be extracted, thereby becoming "stranded assets" (McGlade and Elkins, 2015). A rapid and significant reassessment of the value of these assets could "spark a pro-cyclical crystallisation of losses and lead to a persistent tightening of financial conditions: a climate Minsky moment" (Carney, 2016, 2).

Physical and transition risks can materialise in many ways (Chart 1), with several second-round impacts and spillover effects that can affect all agents in the economy (sovereigns, companies and households). Although physical and transition risks are usually analysed separately, they are interconnected (NGFS, 2019b). For instance, a rapid low-carbon transition decreases the physical risks of climate change but does not eradicate them.

\section{Chart 1 - Channels and spillovers for the materialisation of physical and transition risks}




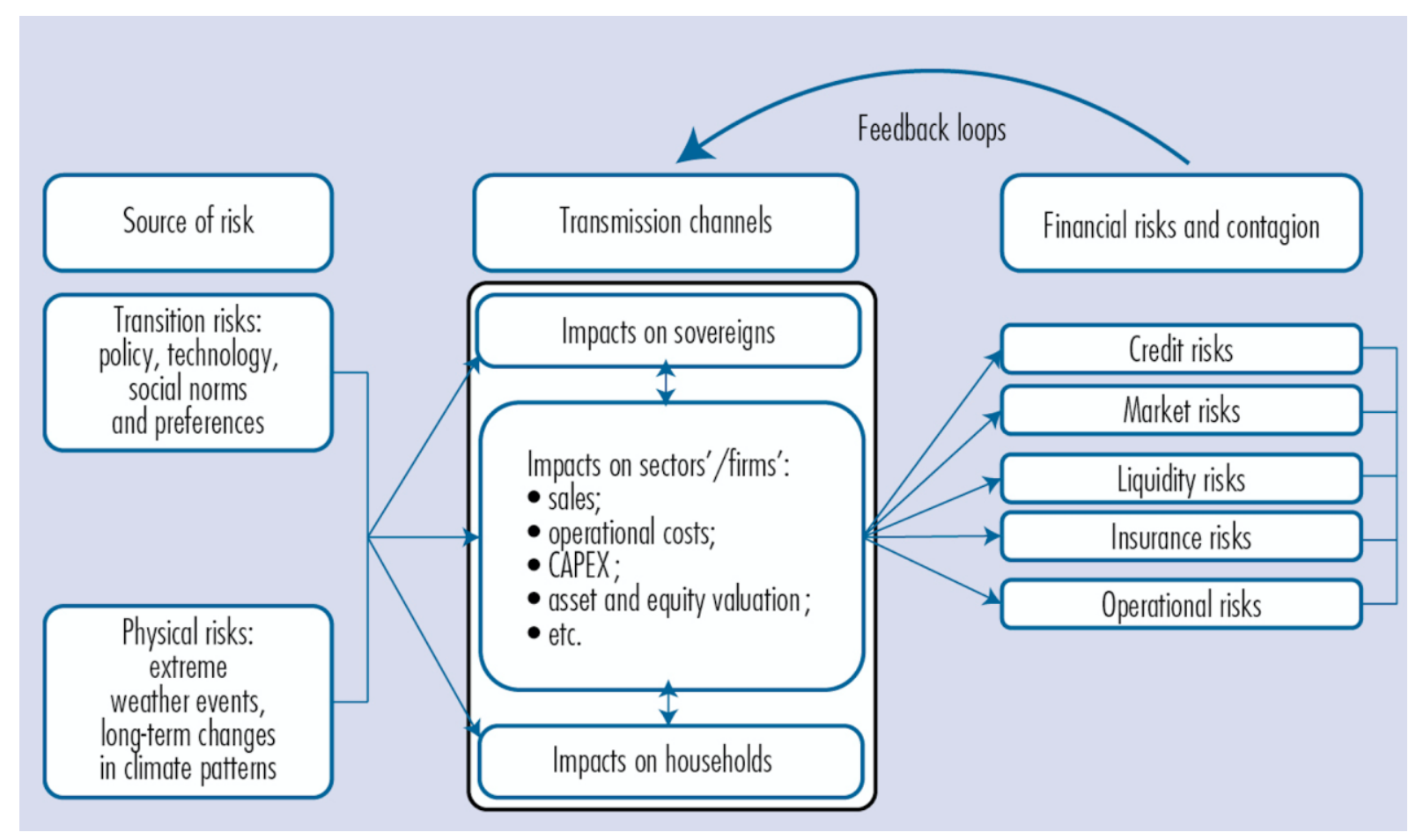

Source: Bolton et al. (2020b)

\section{Difficulties for markets to price in climate-related risks: from data gaps to radical uncertainty}

Central bankers broadly acknowledge that climate-related risks are not priced by financial players (NGFS, 2019a). This may be due to two main reasons.

First, comprehensive and standardised information on climate-related risks is still lacking despite progress over recent years as a response to various initiatives from the official sector as well as private industry groups. Indeed, in the efficient market hypothesis (EMH), asset prices reflect perfectly the risk of these assets given the available information (Malkiel and Fama, 1970; Black and Scholes, 1973; Merton, 1974). Available empirical studies do not find a climate-related risk premium in the fair value of assets. The absence of such a premium could be a consequence of the lack of transparency on climate-related risk disclosure. The standardisation and disclosure of climate-related information by companies would thus permit a better functioning market by reducing the information asymmetry (TCFD, 2017). For instance, Article 173 of the French Law on Energy Transition for Green Growth requires financial firms to disclose the climate-related risks they are exposed to and how they plan to manage them.

A second, fundamental reason why asset prices do not reflect climate-related risks relates to the deep or radical uncertainty related to climate change (Chenet et al., 2019). Physical risks are particularly difficult to measure because of the uncertainty related to Earth systems processes themselves. For instance, many tipping points remain difficult to estimate with precision (IPCC, 2018; Lenton et al., 2019). Crossing them can 
generate tipping cascades in other Earth systems (Steffen et al., 2018), leading to an even higher complexification of risks. Moreover, their impacts on socioeconomic systems can be highly nonlinear. As a result, the possibility of extreme values cannot be ruled out: "deep structural uncertainty about the unknown unknowns of what might go very wrong is coupled with essentially unlimited downside liability on possible planetary damages" (Weitzman, 2011, 275).

Transition risks are also subject to deep or radical uncertainty. Indeed, it is increasingly understood that mitigating climate change amounts to an unprecedented socioeconomic challenge (NGFS, 2019), involving the replacement of existing technologies, infrastructure and even lifestyles over a very short time frame. Whereas standard economic theory considers that imposing a carbon price suffices to internalise current environmental externalities - and therefore to measure climate-related risks -, a growing literature argues that carbon pricing will not be sufficient (IPCC, 2014) for many reasons. ${ }^{6}$ Overall, this uncertainty implies that even a more systematic disclosure of climate-related exposure data may not be sufficient for markets to fully price in and help manage climate-related risks.

\section{A challenging match with traditional risk management measures}

Standard risk management techniques rely on estimates of probability distributions for underlying variables. This is the case of tools such as Value-at-Risk (VaR) or Expected Shortfall (ES). However, the very nature of climate-related risks makes it difficult to specify both frequentist and subjective probabilities. Whereas "risk" is associated with an analytical framework where the probabilities of future events are known, "uncertainty" refers to a situation where we have no knowledge on probabilities (Knight, 1921; Keynes, 1936). This fundamental distinction is critical when considering climate-related issues, including for this paper.

Indeed, this fact has several important implications for the identification of measures to better capture climate-related risks. One is that, in all likelihood, backward-looking probabilistic approaches will not be able to assess climate-related risks properly. Another is that alternative approaches based on a green taxonomy may also prove insufficient. Indeed, a limitation of any taxonomy is that, by construction, it offers only a static view of the reality it depicts (Caldecott, 2019).

\footnotetext{
${ }^{6}$ For instance, many structural challenges "such as the design of cities, industrial supply chains and production networks, respond weakly, or slowly, or both, to marginal price changes" (Hepburn, Stern and Stiglitz, 2020); massive public investments in research and development and infrastructure may be essential to enable low-carbon lifestyles (Aglietta and Espagne, 2016; Krogstrup and Oman, 2019; Mazzucato, 2015); technological barriers to a smooth decarbonisation path may arise regardless of existing carbon prices and public investments (Moriarty and Honnery, 2016); a transition away from fossil fuels can affect the balance of power between states, reconfigure trade flows and transform the nature of conflicts (IRENA, 2019); the relationship between energy and GDP is subject to many theoretical debates that are not yet accounted for by existing climate-economic models (Keen, Ayres and Standish, 2019; The Shift Project and IFPEN, 2019).
} 
When dealing with the radical uncertainty related to climate change, new forward-looking approaches are therefore needed (King, 2017; Maier et al., 2016). Methodologies based on scenarios are one of them. Unlike probabilistic approaches to financial risk management, they seek to set up plausible hypotheses for the future without attributing a probability of occurrence to each of them. Central banks have promoted their use to design and conduct climate stress tests (Allen et al., 2020; Batten et al., 2016; Regelink et al., 2017).

The next sub-section describes the specific challenges related to accounting for climate-related risks in the collateral framework and the ensuing methodological choices.

\section{b. THE RATIONALE FOR FACTORING CLIMATE-RELATED RISKS INTO THE COLLATERAL FRAMEWORK}

\section{A reminder of selected guiding principles underpinning a central bank's collateral policy}

Central banks' collateral policies are far from uniform (BIS, 2013, 2015). They are the result of various factors, which include the structure and development of the financial system through which the central bank operates, the types of instruments it deploys to implement monetary policy, and its history and risk preferences.

Still, a few general guiding principles tend to underpin collateral policies (Bindseil et al., 2017). These include: (i) market neutrality (or residual risk equivalence), meaning that the collateral framework should avoid creating market distortions and treating similar assets or issuers differently; (ii) a level playing field across counterparties, meaning that the collateral framework should not prevent any eligible monetary policy counterparties from participating in liquidity providing operations (this consideration is key for ensuring that monetary policy impulses are transmitted as uniformly as possible across the financial system and the economy); (iii) simplicity (or operational efficiency), meaning that the collateral framework should be smoothly and safely manageable by both the central bank and its eligible counterparties without resulting in undue operational complexity; and (iv) adequate risk protection, meaning that the collateral accepted must be of a quality such that, in the event a counterparty defaults, the central bank can realise the collateral in the market with a high probability of recovering the full amount of its claim. The collateral framework must therefore adequately limit the credit, market and liquidity risks associated with the collateral accepted. Overall, climate-related adjustments to the collateral framework should follow these generic guiding principles as closely as possible.

No action, protective actions, proactive actions? 
In principle, when considering whether to factor climate-related risks into its collateral framework, a central bank may choose from three courses of actions, depending notably on its assessment of potential mispricing of climate-related financial risks by markets (and rating agencies) and its own ability to identify/quantify this level of mispricing.

- No action. This approach rests on the assessment that markets are efficiently processing all climaterelated data and information available to them or that any mispricing is not material enough to be concerning. Efficient markets and/or active fiscal policies are considered to be paramount in correcting any potential mispricing, remediating negative externalities, and reallocating capital away from carbon intensive to low-carbon activities. Assuming market efficiency in pricing climate-related financial risks may however be at odds with the assessment, broadly shared among central banks (NGFS, 2018, 2019), that markets are currently not pricing in climate-related externalities (as discussed above). It is also at odds with ongoing work to incentivise financial institutions to enhance their own protective measures against climate-related financial risks (TCFD, 2017).

- Protective actions. Under this approach, the central bank acts to protect its balance sheet against climate-related risks in the same way it would against other financial risks, irrespective of whether markets are efficient or not. This approach raises new questions from an operational as well as a risk management perspective. In particular, in protecting against climate-related risks, should the central bank comply with the "standard" principles guiding its collateral policy or are there reasons to consider that the very nature of climate-related risks calls for deviations or adaptations? A case in point, for instance, is the "residual risk equivalence" principle, which seeks to equalise residual risks across assets and asset classes. ${ }^{7}$ Even when considering climate-related risk measures through a protective approach, the way in which this principle should be interpreted and implemented is a source of complexity. Indeed, one way to do so could be to apply climate-related risk measures when defining the central bank's risk tolerance threshold, i.e. before applying risk control measures (such as haircuts and so on) to achieve residual risk equivalence. Yet, this would most likely be akin to the central bank taking a stance about whether an economic sector or an issuer is effectively committed (or not) to a good transition path. Given the current institutional environment and technological knowledge, this would run the risk of interfering grossly with market activity and overstepping into the realm of industrial policy. Another interpretation of the principle could be to apply climate-related measures only as risk control measures, similarly to those applied to other risks. The challenge of doing so however is to be able to design asset-specific

\footnotetext{
${ }^{7}$ This guiding principle is one way for central banks to ensure that, given their predefined risk tolerance, the collateral policy is "market neutral".
} 
climate-related risk mitigation measures. While proposals in that direction exist, it is unclear whether they are actually equal to their ambition.

- Proactive actions. In this approach, collateral measures taken by the central bank seek to actively contribute to the transition towards a carbon-neutral economy by influencing market practices and prices. This approach is relevant notably if the central bank determines that climate-related risks may impair the smooth transmission of monetary policy and that collateral measures are adequate tools to help prevent or mitigate such impairment. This option implies going beyond quantifying and mitigating the climate-related financial risks not accounted for by credit ratings, and therefore playing a proactive role in the transition. It may however be difficult to reconcile with the standard practice of leveraging as much as possible on the free functioning of financial markets. As a general matter, proposals falling under proactive actions build on an interpretation of central banks' mandates, either by calling for its expansion or by arguing that they can serve other objectives than price stability (e.g. Schoenmaker, 2019).

What follows investigates one option consistent with a protective approach. Indeed, proactive measures are likely to raise further questions regarding their compliance with the core remit of a central bank, especially in the Eurosystem context. This issue is out of the scope of this paper.

Technically, the analysis below seeks to shed light on whether "alignment" methodologies could open an avenue for a central bank seeking to factor in climate-related risks while complying strictly with the guiding principles of its collateral policy (as summarised above), especially market neutrality and simplicity.

\section{TOWARDS A "CLIMATE-HEDGING PORTFOLIO APPROACH" - THE CASE FOR "ALIGNING" COUNTERPARTIES' POOLS OF COLLATERAL WITH A TEMPERATURE TARGET, AND SOME METHODOLOGICAL CHALLENGES}

\section{A. THE CASE FOR “ALIGNMENT” METHODOLOGIES AS A PROXY FOR TRANSITION RISKS}

Whichever the approach, the integration of climate-related risks into the collateral framework faces the problem identified above: the radical uncertainty related to climate change. Indeed, proposals aimed at providing a measure of climate-related risks often rely on uncertain variables and parameters. Typically, they must determine which policies will be implemented (e.g. which carbon prices), how each sector will be impacted, how each firm within each sector will be impacted, or how future climate-related losses should be discounted. For central banks, this increases the challenges associated with determining, from a climaterelated risk perspective, which assets could be accepted as collateral and under which conditions (e.g. which haircuts should be applied, concentration rules, etc). 
One avenue not yet considered for the purpose of central banks' operational policies consists in building on recent advances in the financial industry, which seek to develop methodologies to measure the "alignment" of a portfolio with a temperature target (see Blood and Levina (2020) as well as Raynaud et al. (2020) for comprehensive reviews and Appendix A for the main features of these methodologies). While there is no formal definition and no single methodological approach, existing "alignment" tools have a broadly similar goal: to provide a mathematical measure to "evaluate the "alignment", "compatibility" or "consistency" of investment portfolios with a given carbon emission trajectory that limits the rise in global temperature below a specific level" (Raynaud et al., 2020, 6), such as the $1.5^{\circ} \mathrm{C}$ or $2^{\circ} \mathrm{C}$ target limits for global warming set by the Paris Agreement (2015).

Generally speaking, a key advantage of such an "alignment" approach is that it removes several layers of uncertainty relative to more traditional approaches to climate-related risks that aim at measuring them in monetary terms. Indeed, these methodologies typically focus on whether companies' business strategies are "aligned" with a specific temperature target. Admittedly, assessing this is an exercise fraught with uncertainty and mired with methodological challenges. For instance, it requires building on an uncertain energy scenario ${ }^{8}$ and determining how a specific firm will "align" with it (see Appendix A). However, this approach avoids adding other sources of uncertainty discussed above (e.g. no assumptions regarding the macroeconomic impact of a carbon price, no modelling to price climate-related risks in monetary value), and as such it can more easily explain why a specific company is more or less (mis)aligned with a climate goal than another.

Because they do not seek to value climate-related risks in monetary terms, the concept of "risk" has a specific definition in these methodologies: a portfolio "misalignment"/incompatibility with the Paris Agreement is risky contingent on a transition to a low-carbon economy taking place. Put differently, the level of "misalignment" can be used as a proxy for transition risk: the warmer the temperature of a pool of assets, the riskier it is.

From a practical viewpoint, using these methodologies would likely represent a structural change in a central bank's risk management practices. Indeed, because, by construction, they yield a non-financial assessment, they depart from the typical risk management toolkit used by central banks. Leveraging them in their collateral policy would mean that central banks would have to review and adjust the way they typically measure, monitor and manage risks on their balance sheet.

The rest of this paper therefore focuses on how "alignment" methodologies could be used by central banks for their collateral framework, as a relevant proxy for transition risks. The focus on transition risks is

\footnotetext{
${ }^{8}$ Most methodologies rely on scenarios developed by the International Energy Agency (see Raynaud et al., 2020).
} 
justified by the fact that the European Union has committed to be climate neutral by 2050 (European Commission, 2020).

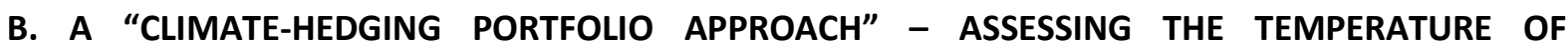 COUNTERPARTIES' POOLS OF COLLATERAL}

Generally speaking, applied to a central bank's collateral policy, this approach would entail:

(i) identifying and selecting existing "alignment" methodologies and metrics that capture the extent to which assets and issuers contribute to meeting the Paris Agreement's target limit of $2^{\circ} \mathrm{C}$ (or $\left.1.5^{\circ} \mathrm{C}\right)$;

(ii) considering the collateral a counterparty pledges to participate in liquidity providing operations as a portfolio of assets; and

(iii) measuring and monitoring its "temperature" over time by reference to a benchmark value.

Importantly, in this approach, the central bank would not focus on the level of climate-related risks asset by asset. It would rather assess and monitor the "temperature" of the pools of collateral pledged by each of its counterparties.

Such a logic would depart from the traditional practice of central banks, including the Eurosystem, in terms of collateral management, consisting in identifying eligible assets and applying risk control measures at the individual asset level. By contrast, the approach sketched above would imply that a counterparty is responsible for ensuring that the pool of assets it has pledged is "aligned" with a given climate target as measured and ascertained by a third party (as discussed in the next section). That said, existing collateral rules already lean towards such a portfolio logic. This is the case, for instance, of rules for a counterparty's pool of collateral imposed by the Eurosystem, such as the concentration limit for uncovered bank bonds.

An important advantage of this approach is that it would likely be compatible with critical principles of the collateral framework such as "market neutrality", "residual risk equivalence", or "open market economy favouring an efficient allocation of resources". Indeed, by adopting a "climate-hedging portfolio approach", a central bank can achieve two objectives at the same time: adjusting its collateral framework to make it compatible with the Paris Agreement (so as to manage transition risks), while leaving it to counterparties to flexibly manage and optimise their collateral pool subject to a "temperature" constraint. In contrast to other options such as the a priori exclusion of specific sectors or assets from the collateral universe, this approach would avoid the need for a central bank to decide on which sector or asset is carbon-intensive. If one considers that the approach of this paper still goes against market neutrality (given that it could send 
new signals to the market to the detriment of certain carbon-intensive assets/issuers and to the benefit of greener assets/issuers), it can still be argued that such an approach is more compatible with market neutrality than all other available approaches. Moreover, such questions should be assessed in light of recent debates on the relevance of market neutrality when it comes to address "prevailing and deep-seated market failures" such as climate change (Schnabel, 2020).

\section{SELECTED METRICS AND THE COLLATERAL UNIVERSE COVERED BY THE STUDY}

This section has so far discussed in general two novelties aimed at better capturing climate-related transition risks in the collateral framework in the context of radical uncertainty: (i) the use of non-financial "temperature alignment" metrics as a proxy for transition risks; (ii) a portfolio-based approach to assessing counterparties' pools of assets (rather than an asset-by-asset risk assessment). This type of approach makes it possible to overcome some of the uncertainties and methodological difficulties involved in studying the financial implications of transition shocks.

We will now discuss their applicability to collateral pools, by focusing on the "alignment" criteria selected for the purpose of this study and the type of assets covered by it.

\section{"Alignment" criteria selected for the purpose of this study}

The ultimate "alignment" criterion varies from one provider to another, with three main distinct families of "alignment" methods and their corresponding "alignment" metric: GHG emission gaps compared to a temperature target, technological metrics, and ratings based on a multi-criteria approach (see Appendix B for further details).

For the purposes of this analysis of collateral data, we chose to select three distinct criteria to represent different approaches and to observe eventual discrepancies. The choice of these criteria is the result of a compromise between their relevance for the analysis of the assets under consideration and their availability in the data made available by two data providers, Carbon4 Finance and S\&P Trucost. The selected metrics are:

1. Relative gap (in \%) between historical and projected emissions over a predefined period (20122023) and a $2^{\circ} \mathrm{C}$ emission budget computed based on the Science Based Targets Initiative (SBTI) trajectory, starting from base year 2012. This metric corresponds to the first type of "alignment" method presented in Appendix $A$. The reference value for the $2^{\circ} \mathrm{C}$ "alignment" is thus $0 \%$. If positive, it describes an overshoot; if negative, the entity does better than the SBTI target. In the data that S\&P Trucost made available to us, the carbon budget corresponds to Scope 1 and Scope 2 emissions. The same scope of analysis is applied to credit institutions or financial corporations. 
This means that the analysis does not take into account GHG emissions financed through the loans and investments of financial institutions. From a risk management perspective, this is a limitation.

2. Overall rating according to the Carbon Impact Analytics (CIA) methodology developed by Carbon4 Finance. This metric corresponds to the third type of "alignment" method presented in Appendix A, using a multi-criteria approach. The score ranges from 1 (best score) to 5 (worst score). For a given economic entity, this overall rating results from different sub-analyses:

- The measure of the GHG emissions induced by the entity, including Scope 1, Scope 2 and Scope 3 emissions, both downstream and upstream.

- The measure of the GHG emissions avoided by the entity, also within the three scopes. According to the Carbon4 Finance methodological handbook, this metric reveals how an entity or firm is "disrupting its sector, either through more efficient processes or through carbon-efficient products or services". Carbon4 Finance uses the "Carbon Impact Ratio" indicator, i.e. the ratio of avoided emissions divided by induced emissions, to describe the performance of a firm.

- A qualitative forward-looking score to capture the likely evolution of an entity's carbon impact. This type of evaluation includes "an analysis of investments and R\&D expenditures that will contribute to decreasing carbon emissions, as well as an analysis of the entity's positioning and strategy regarding the low-carbon transition".

These three aspects of the analysis follow sector-specific calculation modules and evaluation grids, based on expert knowledge and based on Carbone 4 group's expertise in carbon consulting. For the specific case of financial institutions, financed emissions are accounted for in induced emissions. They are estimated based on public information on the assets held by the institution, using a sectoral top-down approach similar to the P9XCA method (Rose, 2014), for example. As regards central governments, their overall rating is based on the following three indicators: carbon intensity of GDP, GDP reliance on fossil fuel profits, and country INDC compatibility with IEA's 2DS scenario.

Table 1 gives comparison values for the two "alignment" metrics we selected.

Table 1. "Alignment" metrics: target and benchmark

\begin{tabular}{|l|c|l|}
\hline Metric & "Alignment" Target & Benchmark \\
\hline S\&P Trucost relative GHG & $0 \%$ & $30 \%$ (Euro \\
(Scope 1 + Scope 2) overshoot & & Stoxx 600) \\
(2012-2023) & & \\
\hline
\end{tabular}




\begin{tabular}{|l|l|l|}
\hline Carbon 4 Finance & $\begin{array}{l}1.5 \text { (Euronext Low } \\
\text { Carbon 100) }\end{array}$ & $\begin{array}{l}3.5 \text { (CIA } \\
\text { database) }\end{array}$ \\
\hline
\end{tabular}

3. Although it is not a metric used by carbon data providers as a final criteria of "alignment", we also selected the GHG emission intensity metric (Scope 1, 2 and 3 GHG emissions (tCO2e) per EUR million of debt) for several reasons. First, GHG emissions are the primary data and do not depend on any target or reference scenario: hence, it is merely descriptive. Second, it allows us to compute the carbon footprint of a portfolio taking a "balance sheet" approach (see Methodological principles in Appendix A). Third, in principle, all eligible asset classes could be analysed using this metric, even credit claims or asset-backed securities (ABS). Note however that this work has not yet been carried out for these two asset classes, but could be done on a sectoral basis. It could enable us to expand the scope of this analysis to all eligible asset classes. This third metric was also provided to us by Carbon4 Finance.

\section{Eurosystem eligible and pledged collateral covered by this study}

"Alignment" methods and the extra-financial criteria they provide have typically been designed for private investors managing equity or bond portfolios, focusing mainly on corporate assets (the databases of the providers essentially cover mid- and large-cap companies).

Yet, the Eurosystem universe of eligible collateral is broad and includes assets beyond those issued by large non-financial corporations. As a result, applying the selected methodologies to the full set of eligible assets confronts us with some methodological/operational choices. This challenge is not trivial as it arises for several types of eligible assets, which are also typically pledged with the Eurosystem (see Appendix C for further details). Broadly speaking, solutions/choices can be found/made relatively easily for a first type of assets issued by entities such as credit institutions, other financial corporations, national and supranational agencies, and governments. By contrast, more critical challenges arise when applying the selected methodologies to a second type of assets issued by entities that are not easily identifiable, such as nonmarketable assets and asset-backed securities. This study covers the first type of assets but not the second one. It focuses on marketable eligible assets only.

The coverage rate of eligible and pledged Eurosystem collateral covered by the study is given by analysing the entire universe through the prism of the three previously introduced metrics (relative emission gap, overall rating and GHG emission intensity per EUR million invested), obtained by matching Eurosystem collateral data with data made available by the two providers. This analysis is "issuer-driven", in the sense that the entities issuing eligible collateral are the matching key between the collateral data and the carbon 
data. The statistics presented are for a given date in May 2020: due to the temporal inertia of these measurements over the first half of 2020 (due to the Covid-19 crisis), we have chosen to disregard the time dimension of the topic at this stage..$^{9}$

Table 2 shows that the metrics from the selected data providers cover a significant part of all eligible and pledged marketable assets ${ }^{10}$. In terms of the number of issuers of eligible securities, the S\&P Trucost and Carbon4 Finance universe covers 370 and 660 entities, respectively, out of a total of approximately 1,670. Comparatively, in May 2020, some 300 issuers accounted for more than $90 \%$ of eligible collateral. Of these, 115 are covered by S\&P Trucost and 215 are covered by Carbon4 Finance. Thus, reaching 90\% of eligible collateral covered would not necessarily require us to include many more issuers. Conversely, the last $10 \%$ of eligible nominal amounts would take longer to fill because of the long "tail" of smaller issuers. However, the total number of issuers remains limited compared to the size of the databases of these providers, which are around 15,000 and 3,000 lines, respectively.

Table 2. Global coverage rates ${ }^{11}$ of carbon databases for marketable assets (date: May 2020)

\begin{tabular}{|l|r|r|}
\hline & \multicolumn{2}{|c|}{ Coverage rate } \\
\hline & Carbon4 Finance & \multicolumn{2}{|c|}{ S\&P Trucost } \\
\hline Eligible & $80 \%$ & $79 \%$ \\
\hline Pledged & $61 \%$ & $63 \%$ \\
\hline
\end{tabular}

The differences in the coverage rates for the two providers are mainly due to the proportional difference between the eligible and pledged collateral of the different asset classes. For example, national government bonds, which are $98 \%$ covered by the $\mathrm{CIA}$, represent around $52 \%$ of eligible marketable collateral but only $18 \%$ of pledged collateral. This partly explains why the Carbon4 Finance data exhibit a lower coverage rate for pledged collateral than for eligible collateral. It is useful to study the coverage rate of these providers for each issuer type. For robustness and confidentiality reasons, our analysis focuses only on the issuer types with more than 10 entities covered by the providers: corporates, credit institutions and other financial corporations, and central governments. Table 3 presents the obtained coverage rates for these three categories of issuers. The S\&P Trucost database also covers central governments, but the metrics provided are different to those for other asset classes. We therefore decided not to take them into account in this analysis.

\footnotetext{
${ }^{9}$ Appendix D documents the stability of the results over time.

10 In the second quarter 2020, the marketable eligible assets amount to 15,200 EUR bn and the mobilisation of marketable collateral amount to 1,650 EUR bn (nominal amounts). For more details, see the ECB public data at https://www.ecb.europa.eu/paym/coll/charts/html/index.en.html.

${ }^{11}$ All coverage rates in this paper are based on the amounts (in Euros) eligible and/or pledged.
} 
Table 3. Coverage rates of marketable assets by issuer types (date: May 2020)

\begin{tabular}{|c|c|c|c|}
\hline & \multirow{2}{*}{ Issuer category } & \multicolumn{2}{|c|}{ Coverage rate } \\
\hline & & Carbon4 Finance & S\&P Trucost \\
\hline \multirow{4}{*}{ Eligible collateral } & Central governments & $98 \%$ & (Not used) \\
\hline & Corporates & $83 \%$ & $63 \%$ \\
\hline & $\begin{array}{l}\text { Credit institutions } \\
\text { (excluding agencies) }\end{array}$ & $64 \%$ & $45 \%$ \\
\hline & $\begin{array}{l}\text { Other financial } \\
\text { corporations (excluding } \\
\text { ABS) }\end{array}$ & $70 \%$ & $57 \%$ \\
\hline \multirow{4}{*}{$\begin{array}{l}\text { Pledged } \\
\text { collateral }\end{array}$} & Central governments & $97 \%$ & (Not used) \\
\hline & Corporates & $40 \%$ & $30 \%$ \\
\hline & $\begin{array}{l}\text { Credit institutions } \\
\text { (excluding agencies) }\end{array}$ & $72 \%$ & $56 \%$ \\
\hline & $\begin{array}{l}\text { Other financial } \\
\text { corporations (excluding } \\
\text { ABS) }\end{array}$ & $70 \%$ & $53 \%$ \\
\hline
\end{tabular}

\section{TESTING CLIMATE-RELATED METRICS ON THE EUROSYSTEM'S ELIGIBLE AND PLEDGED MARKETABLE COLLATERAL - STYLISED FACTS}

\section{A. AGGREGATE STYLISED FACTS FOR SELECTED METRICS}

All the statistics presented below are weighted with nominal outstanding amounts. As the coverage rate is partial as mentioned above, these statistics do not reflect the "exact alignment" of eligible and pledged collateral.

Chart 1 shows the results for the first metric, i.e. the relative gap. It shows that around 25\% of the analysed eligible collateral issued by financial and non-financial corporations are " $2{ }^{\circ} \mathrm{C}$ aligned" according to the relative emission gap criterion (period 2012-2023); around 50\% of this analysed eligible corporate collateral corresponds to companies with a GHG overshoot of between $0 \%$ and $50 \%$ during this period. For eligible collateral issued by credit institutions, the proportion of "aligned" assets rises to $50 \%$. However, S\&P Trucost's narrower perimeter of analysis (Scope1 and Scope 2) implies that these institutions appear "more aligned" since their "financed" GHG emissions (a category of emissions included in Scope 3) are not accounted for. 


\section{Chart 1. Relative emission gap (\%) of eligible collateral}

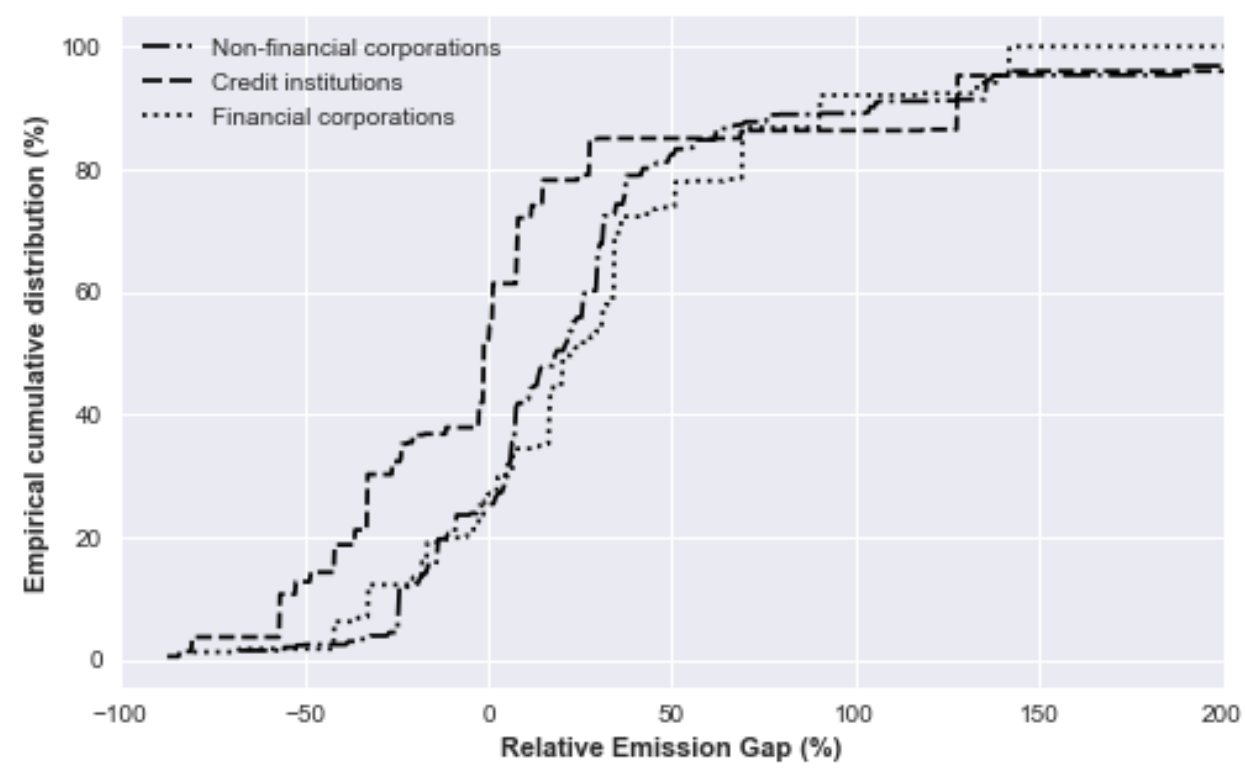

Chart 2 shows the results for the second metric, i.e. Carbon4 Finance's CIA rating. It shows that only a minority of the eligible collateral falls below the 1.5 overall rating, which corresponds more or less to the $2^{\circ} \mathrm{C}$ target limit and to the score achieved by the Euronext Low Carbon 100 Index. About $15 \%$ (in terms of nominal amount) of corporate assets are below this threshold and no credit institution meets this standard. Nevertheless, around $80 \%$ of the eligible corporate collateral and $75 \%$ of eligible collateral issued by credit institutions do better than the average score in the whole $\mathrm{ClA}$ database - which more or less represents the global economy - of 3.5. Chart 2 also shows that central governments are better "aligned" than the average company or credit institution. The high concentration around the overall rating 3 (except for central governments) is due to the fact that this is the default score given by Carbon4 Finance to entities that do not belong to "high-stakes" carbon sectors. ${ }^{12}$

\footnotetext{
${ }^{12}$ According to the Carbon4 Finance methodology, "high-stakes sectors" are energy, GHG emission intensive, capital goods and institutional sectors. This matches the high-stakes sector classification of the Task Force on Climate-related Financial Disclosures (TCFD).
} 


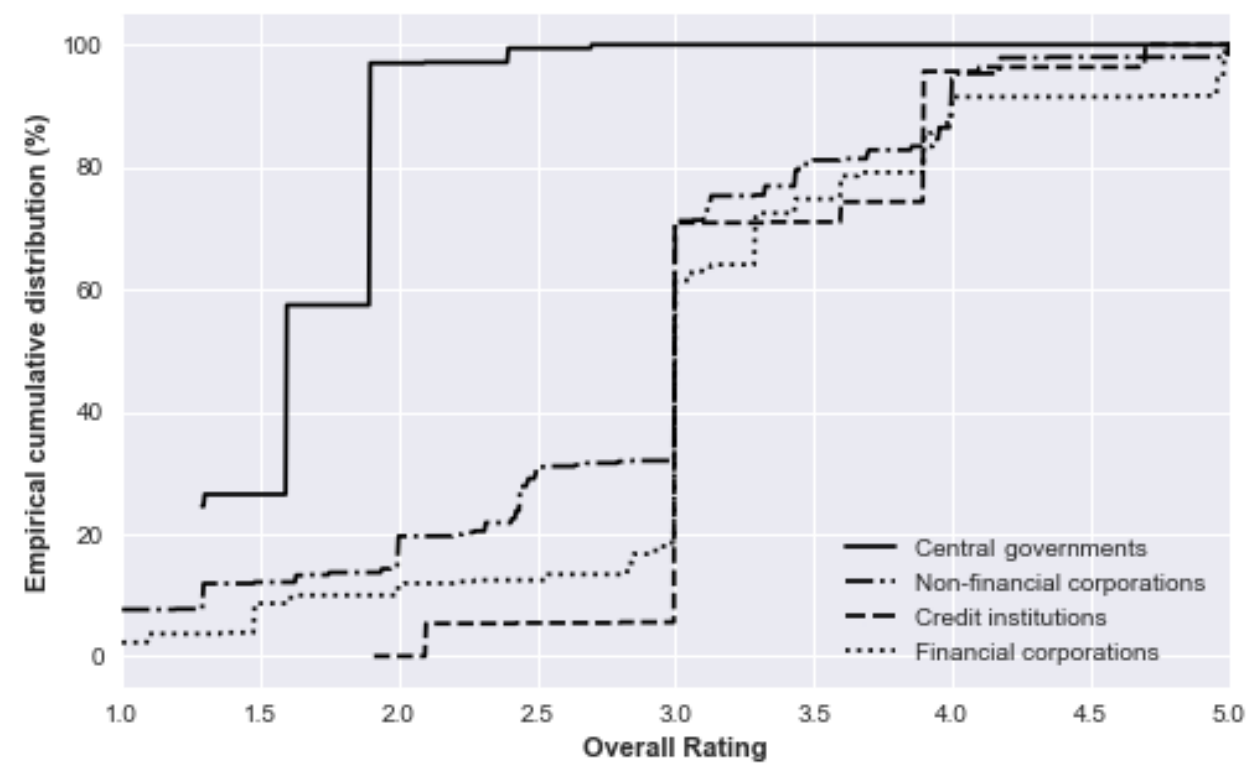

Chart 2. Overall rating of eligible collateral

Chart 3 shows the results for the third metric, i.e. GHG emission intensity. The results are more dispersed than for the two previous metrics. This purely descriptive metric reflects the significant difference between the GHG emission intensities of the various economic sectors represented in the eligible collateral. Regarding non-financial corporate assets, the GHG emission intensity distribution is particularly widespread: almost $40 \%$ of the eligible collateral covered by the data is under 100tCO2e/EUR million of debt and about $20 \%$ is above 1,500 tCO2e/EUR million. For credit institutions, the methodology takes into account financed emissions, which explains the observable pooling effect: since they finance the entire economy, most banks' carbon intensity is concentrated around the overall average intensity, in a 300-700tCO2e/EUR million range. This distribution is also observable for central governments, whose carbon intensity is the ratio of total GHG emitted in its jurisdiction to its public debt. Consequently, the plain curve is not fully comparable with the others. However, using this approximation to compute the carbon footprint of an asset holder is still relevant. 


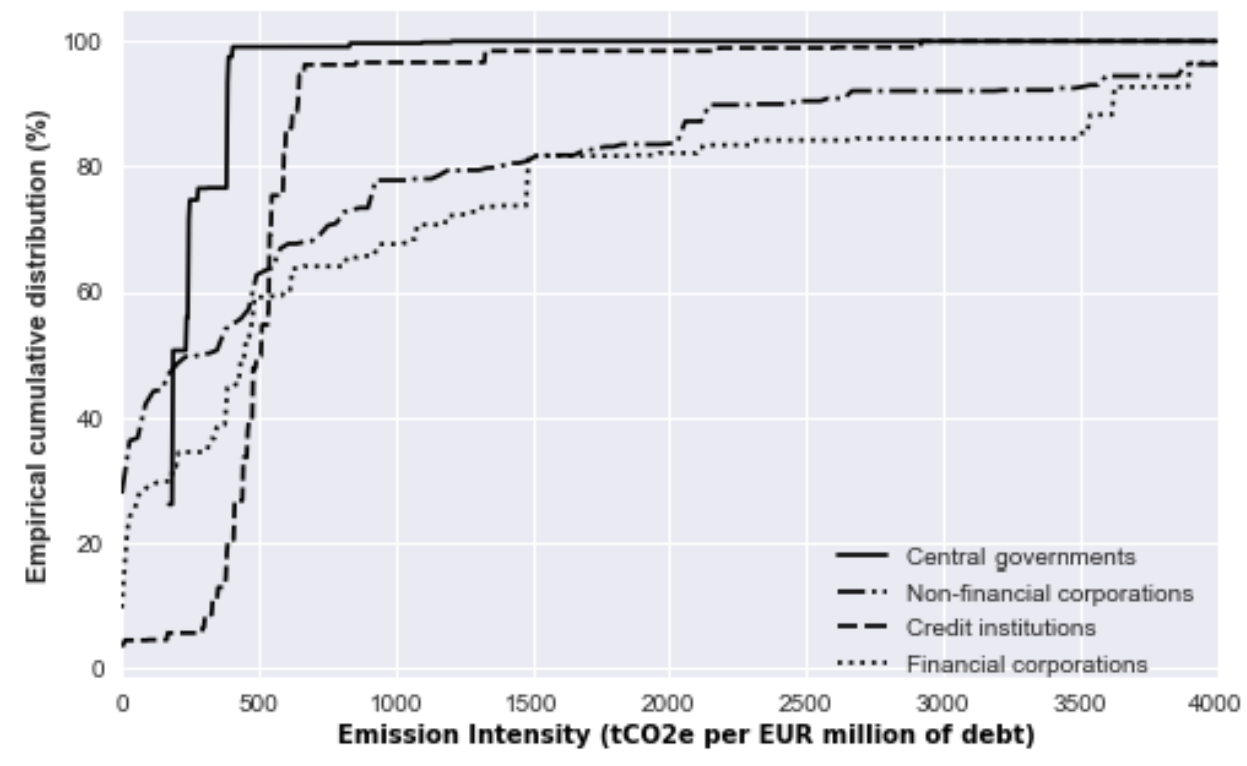

Chart 3. GHG emission intensity of the eligible collateral

The results obtained for eligible collateral are relatively similar to those obtained for pledged assets (see Appendix E for details). This observation holds for the three metrics discussed above (Table 4). This suggests that, within these categories of assets, counterparties tend to pledge collateral apparently without any clear "climate bias".

Table 4. Average scores for eligible and pledged assets issued by credit institutions, non-financial corporations and financial corporations

\begin{tabular}{|l|l|l|l|}
\hline & $\begin{array}{c}\text { Relative GHG emission } \\
\text { gap (\%) }\end{array}$ & \multicolumn{1}{|c|}{ CIA overall rating } & $\begin{array}{c}\text { GHG emission } \\
\text { intensity } \\
\text { (tCO } 2 \text { e/EUR m) }\end{array}$ \\
\hline Eligible assets & 18 & 3.1 & 730 \\
\hline Pledged assets & 12 & 3.2 & 560 \\
\hline
\end{tabular}

Tables 5, 6 and 7 present the average scores for eligible and pledged assets by issuer category.

Table 5. Average scores for eligible and pledged assets issued by credit institutions

\begin{tabular}{|l|c|c|c|}
\hline & $\begin{array}{c}\text { Relative GHG emission } \\
\text { gap (\%) }\end{array}$ & CIA overall rating & $\begin{array}{c}\text { GHG emission } \\
\text { intensity } \\
\text { (tCO } 2 \text { e/EUR m) }\end{array}$ \\
\hline Eligible assets & 10 & 3.2 & 530 \\
\hline Pledged assets & 9 & 3.2 & 510 \\
\hline
\end{tabular}


Table 6. Average scores for eligible and pledged assets issued by non-financial corporations

\begin{tabular}{|l|c|c|c|}
\hline & $\begin{array}{c}\text { Relative GHG emission } \\
\text { gap (\%) }\end{array}$ & ClA overall rating & $\begin{array}{c}\text { GHG emission } \\
\text { intensity } \\
\text { (tCO } \mathrm{e} / \text { EUR } \mathrm{m})\end{array}$ \\
\hline Eligible assets & 33 & 2.9 & 970 \\
\hline Pledged assets & 40 & 3.0 & 1020 \\
\hline
\end{tabular}

Table 7. Average scores for eligible and pledged assets issued by financial corporations

\begin{tabular}{|l|c|c|c|}
\hline & $\begin{array}{c}\text { Relative GHG emission } \\
\text { gap (\%) }\end{array}$ & ClA overall rating & $\begin{array}{c}\text { GHG emission } \\
\text { intensity } \\
\text { (tCO } 2 \text { e/EUR m) }\end{array}$ \\
\hline Eligible assets & 29 & 3.1 & 1070 \\
\hline Pledged assets & 18 & 3.3 & 580 \\
\hline
\end{tabular}

\section{B. STYLISED FACTS FOR COUNTERPARTIES' POOLS OF COLLATERAL}

We now look at the average ratings distribution by assessing counterparties' collateral pools. For each of the three selected metrics, we present (i) a scatter plot jointly representing the size of the pledged collateral pools (node size), their average rating, the coverage rate of available data, and the bank's country of residence, and (ii) a histogram of this distribution among collateral pools with at least one asset covered by available data. The weighting in the histogram is the number of collateral pools, regardless of their size.

Overall, the main stylised facts are:

- The degree of "alignment" widely differs across counterparties' collateral pool. No clear explanatory factor, such as the country of incorporation of the counterparty, stands out to account for this.

- Unsurprisingly considering the results above, most counterparties' collateral pools are "misaligned", and as such exposed to transition risks, though to varying degrees.

Chart 4 shows that, based on the S\&P Trucost data, large differences exist in the coverage rate and average rating of the collateral pools across counterparties, including across those that are incorporated in the same country. ${ }^{13}$ For instance, at the top left of the chart, we can observe that one Spanish counterparty with a relatively large and well-covered pool (above $80 \%$ ) stands out: the relative gap corresponding to its

\footnotetext{
${ }^{13}$ It should be emphasised that there is only a limited number of counterparties for which more than $50 \%$ of the assets in the pool could be assessed.
} 
pool of collateral is almost $-50 \%$, meaning that this pool seems to be highly "aligned" from a climate perspective. In contrast, on the right hand of the chart, one counterparty from "Other countries" with a relatively large yet less well-covered pool (between $40 \%$ and $50 \%$ ) has a positive relative gap of close to $150 \%$, suggesting that it is largely "misaligned" with ambitious climate targets.

Chart 5 shows a relatively symmetrical distribution of pools' relative emission gaps, with a high concentration of counterparties' pools located between a $0 \%$ and $25 \%$ overshoot.

4. Coverage rate and emission gap of the pools, based on $S \& P$ Trucost's methodology
5. Histogram of the pools' emission gap, based on $S \& P$ Trucost methodology
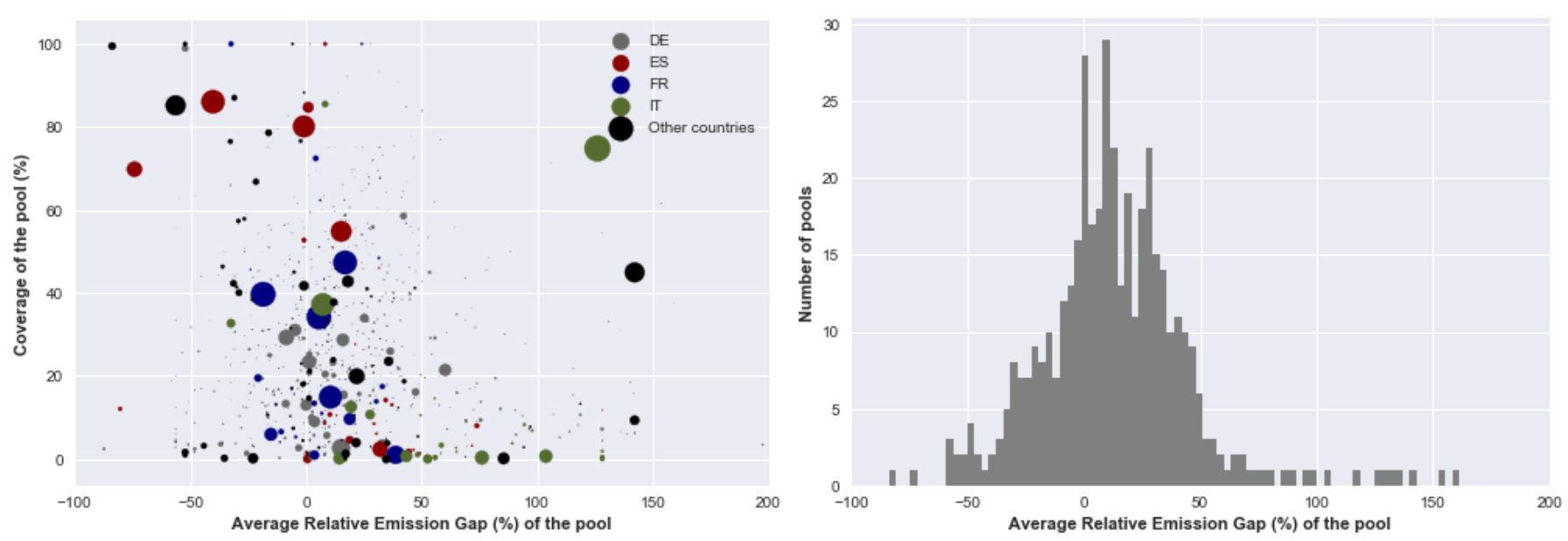

Chart 6 and Chart 7 shows stylised facts based on Carbon4 Finance's CIA metric. Similarly to previous charts, they also show great divergence in terms of "alignment" across collateral pools. Collateral pools exhibiting a rating better than the reference rating $\left(1.5\right.$, which corresponds more or less to the $2^{\circ} \mathrm{C}$ target) are quite rare. This may be partially explained by the averaging effect of the "low-stakes entities", being automatically granted a rating of $3 .{ }^{14}$ The latter fact also explains the concentration around the rating of 3 in the histogram of pools presented in Chart 7. The high concentration around 1.9 in Chart 7 is due to the fact that the banks' collateral pool in one specific country is largely composed of bonds issued by this country's government, which are rated 1.9. When looking at specific countries, Chart 6 reveals that the coverage rate for the biggest French banks is quite centred around $50 \%$ and that their ratings range between 2 and 2.7. The main Italian banks have a high coverage rate but their ratings are more dispersed. The rating of German counterparties' pools also looks quite spread. Chart 6 also reveals a high concentration of small-sized collateral

\footnotetext{
${ }^{14}$ In order to avoid this averaging effect of low-stakes companies, Carbon4 Finance's methodology limits the weights of these companies in the portfolio aggregation step. We did not apply this method here.
} 
pools with a high coverage rate and with an overall rating above 3 . Chart 7 also shows a significant number of pools above the rating of 3 .

6. Coverage rate and overall rating of the pools, based on Carbon4 Finance's methodology
7. Histogram of the pools' overall rating, based on Carbon4 Finance's methodology
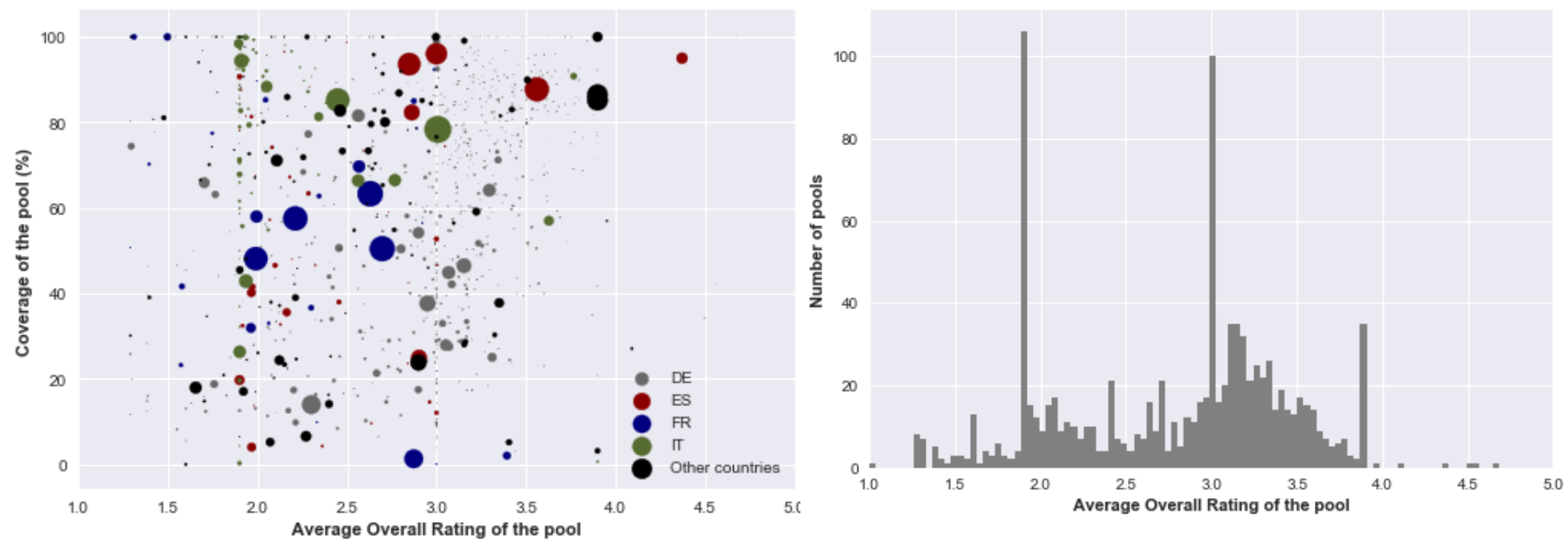

Finally, when looking at GHG emissions, Chart 8 shows that most counterparties' collateral pools have relatively similar intensities (per unit of debt). The largest French and Spanish pools are quite concentrated in the 300-600 tCO2e/EUR million range. The main German and Italian pools are in the same region, but many smaller German pools exhibit emission intensities above 500 tCO2e/EUR million and many smaller Italian pools are closer to 200 tCO2e/EUR million. Chart 9 reveals a pool distribution with a rather flat tail above 500 tCO2e/EUR million. This flat tail of pool average GHG intensity stems from the nature of this metric: at the issuer level, this metric spreads over two to three orders of magnitude. 

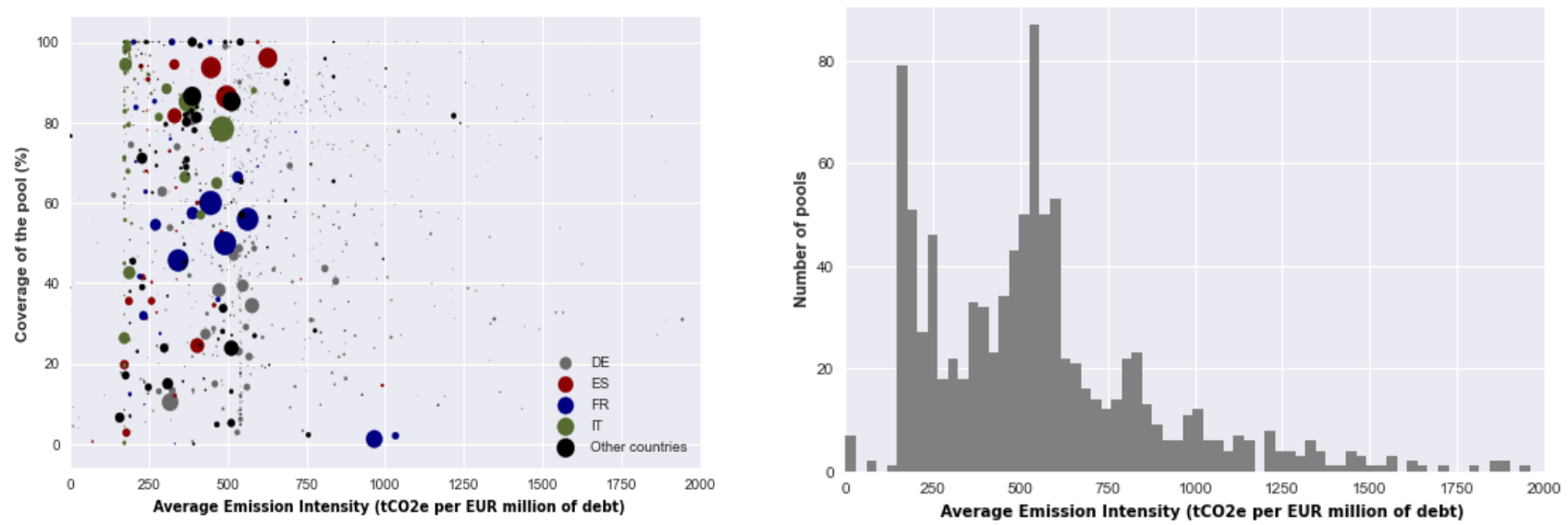

\section{5. “ALIGNMENT”, COLLATERAL AVAILABILITY AND POLICY DESIGN QUESTIONS}

This section looks at an important question for a central bank: what is the amount of eligible collateral that could be considered "aligned", or at least below a certain maximum "temperature level". The answer to this question is critical since the effectiveness of its operational framework typically depends on the availability of collateral in sufficient quantity and quality.

Technically, this question could be formulated as follows: for a given criterion and an associated maximum target level $S$, what is the maximum average amount of collateral that complies with this target?

We provide below a tentative answer to this question, focusing only on the assets issued by credit institutions, and financial and non-financial corporations, without taking sovereign bonds into account (unlike the previous section, in which these assets were covered). ${ }^{15}$ Moreover, we assume that issuers that are not assessed by the providers follow the same rating distribution as issuers of the same category for which an assessment is available. This assumption, while simplistic, is reasonable because it is not clear whether noncovered issuers would tend to fare better or worse than others. Hence, we give random scores to non-covered issuers, according to the score distribution of their category.

\section{A. "AlignMENT" OF Eligible collateral AND COLLATERAL AVAILABILITY FOR MONETARY POLICY PURPOSES}

In the charts presented below, the continuous curves describe the nominal amount of eligible securities issued by banks and corporations that have the average score of $S$, for several random draws of

\footnotetext{
${ }^{15}$ The challenge of including or excluding sovereign bonds is discussed in the next sub-section. At this stage, it is sufficient to note that including sovereign bonds in the analysis below would typically result in increasing the available amount of "aligned" collateral.
} 
scores of securities not included in the "carbon" database. The greyscale stands for several values of a parameter $\delta$, with $\delta$ representing the extent to which the proportions between the different categories of issuers can differ from the current proportions of the pledged collateral. A higher value of $\delta$ is less restrictive and therefore allows for a higher amount. The optimisation problem whose outcome provides these curves is presented in Appendix F. This optimisation serves to avoid unintended consequences in the simulation, notably that all counterparties drastically change the composition of their pools by pledging a much more limited number of asset classes.

Using the S\&P Trucost metric (Chart 10), an "aligned" aggregate amount of eligible assets (reference value: $0 \%$ ) exists that is larger than the nominal amount (before haircuts) that is effectively pledged by counterparties for the same asset classes. Indeed, whereas the current pledged amount shows a positive emission gap of more than 10\%, Chart 10 shows that there would be between EUR 2 trillion and EUR 3 trillion of eligible assets with a negative gap of about 20\%, and between EUR 3 trillion and EUR 4 trillion of eligible assets with no gap at all (0\%). This finding should nevertheless be nuanced since, as mentioned above, S\&P Trucost's assessment of banks' "alignment" is limited to Scope 1 and Scope 2, i.e. it does not account for GHG emissions "financed" by banks.

\section{Eligible nominal amount, as a function of the average GHG emission gap}

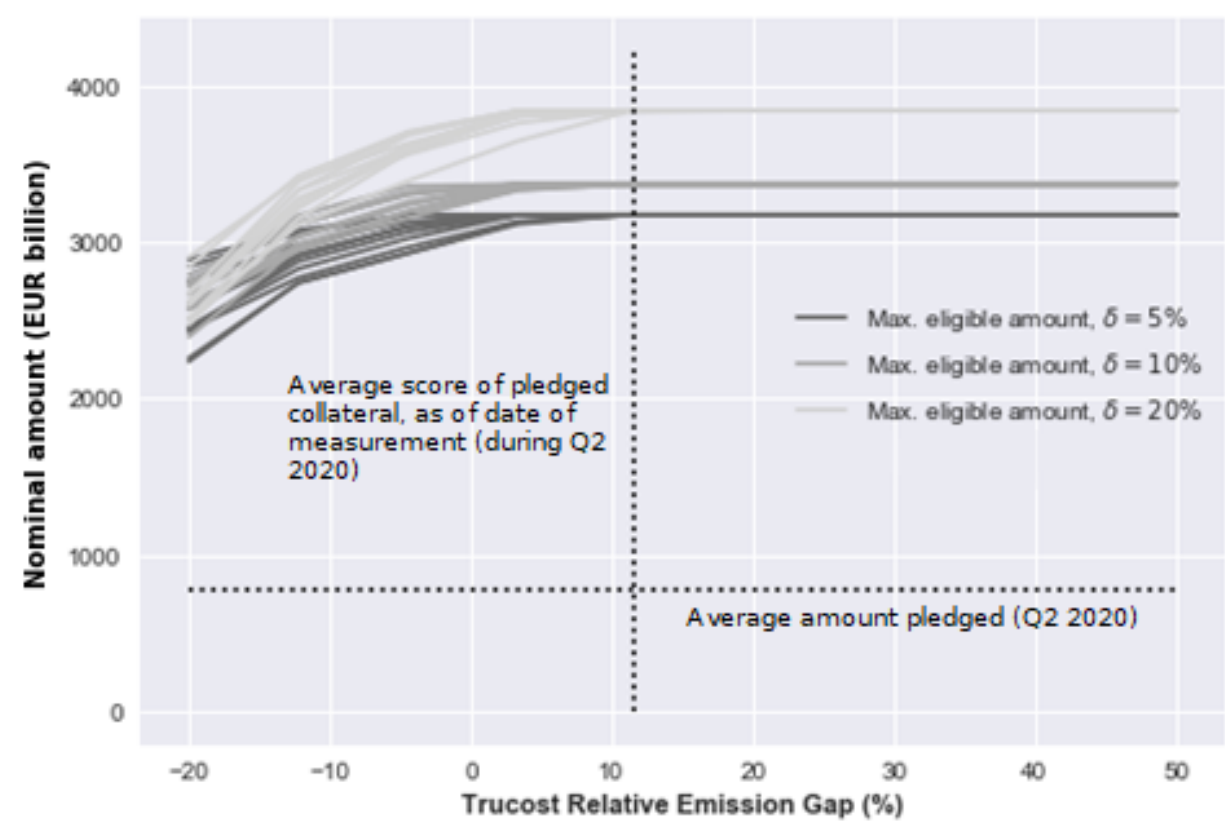

Using Carbon4 Finance's overall rating (Chart 11), the volume of eligible assets shrinks much more rapidly as one moves towards the reference rating (i.e. overall rating of 1.5 or 2). Even for an average rating of 2 , the volume of eligible assets becomes smaller than the nominal volume of pledged assets, for the same 
categories of issuers, i.e. respecting the optimisation problem discussed above. Indeed, it ranges from close to EUR 0 to about EUR 500 billion, i.e. much less than the EUR 900 billion currently pledged. The best possible overall rating of the collateral (i.e. where the curves of eligible amounts meet the pledged amounts) would be between 2 and 2.5, which would still be a considerable improvement from the current overall rating of about 3.2. These findings may be partially explained by the fact that many issuers have an overall de facto rating of 3 (as discussed above).

11. Eligible nominal amount, as a function of the average overall rating

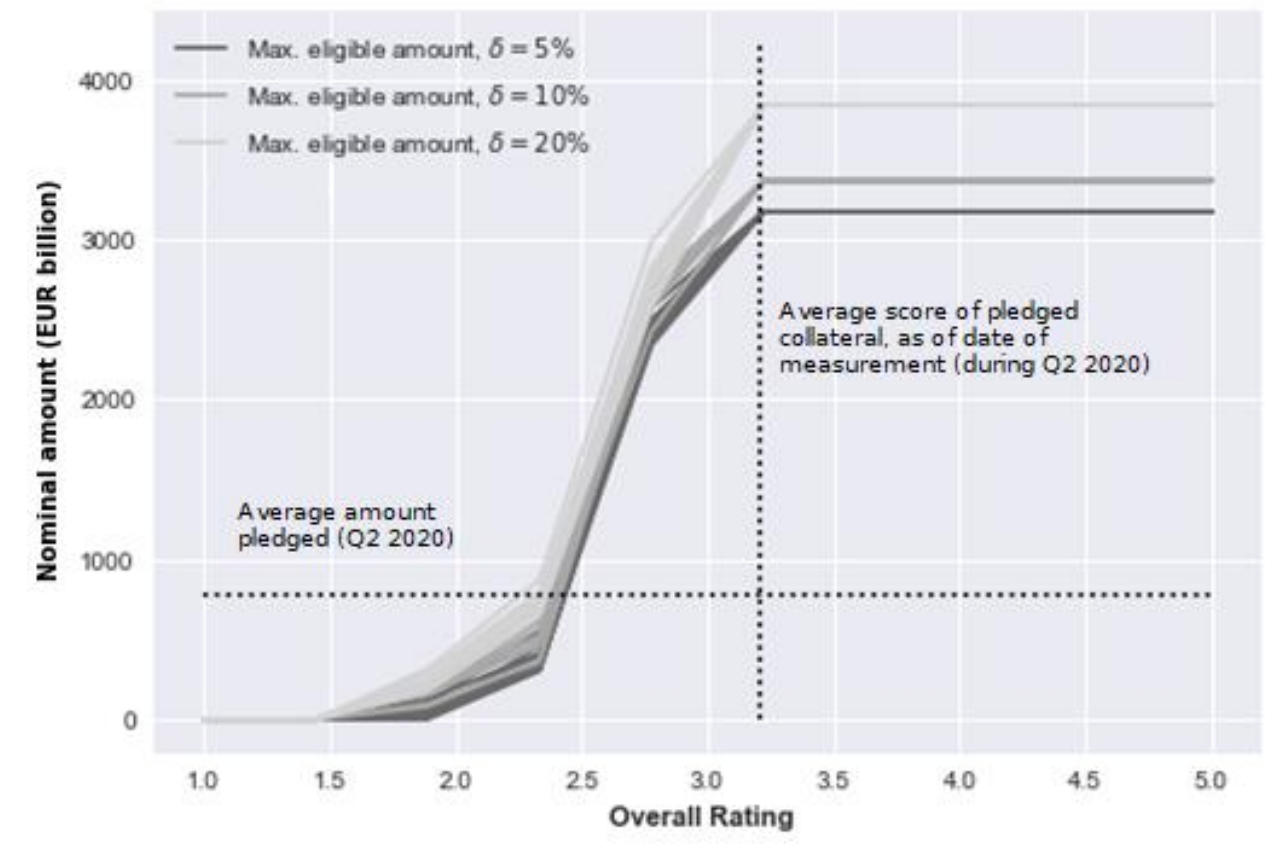

Finally, Chart 12 shows that only a limited volume of eligible assets exhibit an average value of GHG intensity ranging from 570 to 400 tC02e/EUR million. Moreover, there seems to be a volume of eligible securities with an average intensity of 250 tCO2e/EUR million that is higher than the nominal amount of bank and corporate securities pledged by counterparties. This simply reflects the fact that, for these asset classes, the total nominal amount of eligible securities is much higher than that of pledged securities. This suggests that, in theory, the composition of collateral pools could be improved from a GHG emission intensity perspective.

That said, targeting the GHG intensity of assets in aggregate (i.e. irrespective of the economic sector) might not be an efficient strategy from a risk protection perspective. Doing this may lead to overweighting companies operating in sectors which do not greatly aggravate climate change, but do not prevent it either (e.g. services). It could be more meaningful to consider GHG intensity by sector for instance, in addition to relying on forward-looking metrics such as those other metrics selected for the purpose of this paper. 
Chart 12. Eligible nominal amount, as a function of the average GHG emission intensity

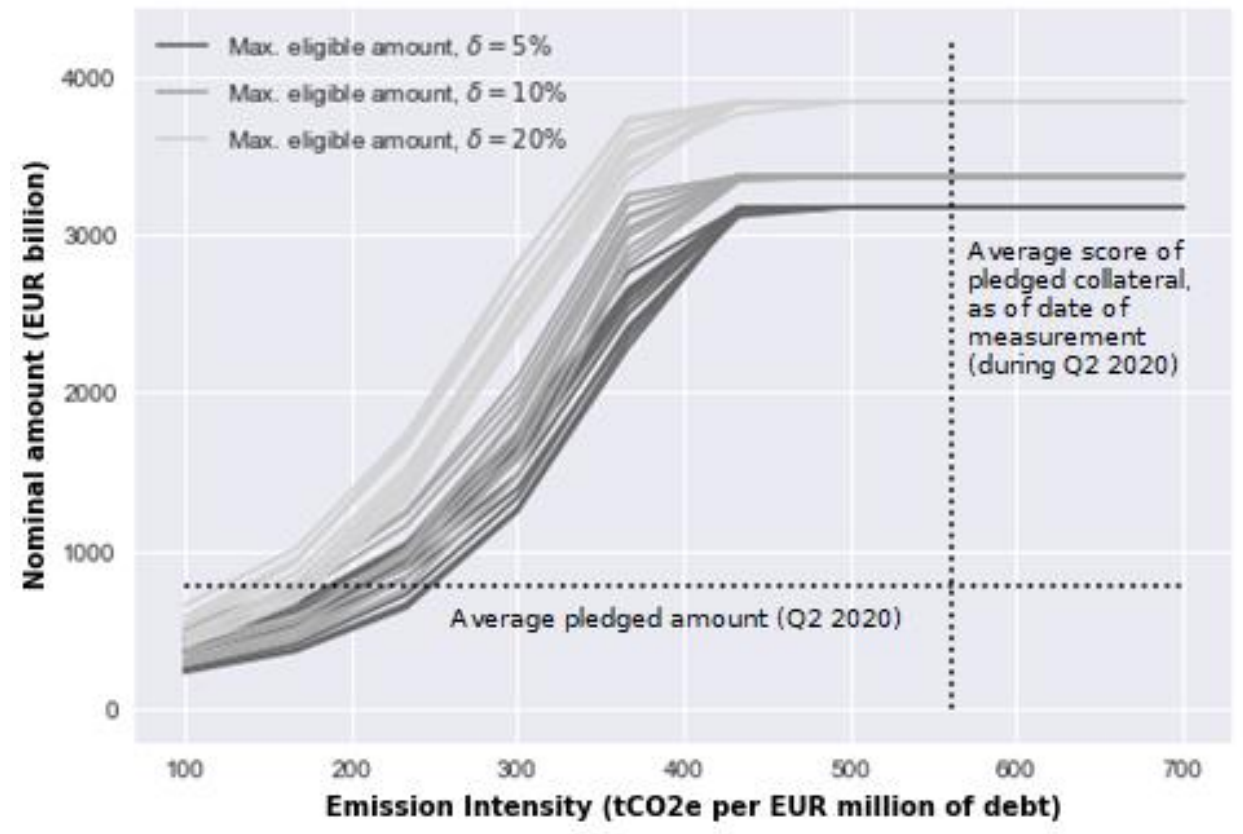

All in all, these results suggest that, prima facie, there seems to be room to reduce the Eurosystem's maximum (nominal) exposure to transition risks (as proxied by the metrics used above) and that this might be achieved without reducing available collateral to such an extent that the central bank may lose its flexibility in running large scale credit operations. ${ }^{16}$ Interestingly, this seems to be the case even for metrics such as Carbon4 Finance's rating, which may be more stringent because they include Scope 3 GHG emissions. That said, these assessments rely on two methodologies only. Further work leveraging other "alignment" methodologies is needed to confirm them.

\section{B. COLLATERAL MOBILISATION, POLICY DESIGN QUESTIONS AND CAVEATS}

Without prejudging whether the stylised facts highlighted above are robust to the use of other methodologies, the experiment also helps identify potential operational implications and associated challenges of "aligning" (or reducing the "misalignment" of) the eligible collateral.

As mentioned in Section $3 \mathrm{~A}$, the experiment considers that, to assess transition-related financial risks embedded in its credit operations, a central bank could monitor the extent to which the pool of collateral a counterparty pledges is "aligned" (or at least less "misaligned") with a specific climate temperature target. A step beyond monitoring could be for the central bank to design a mobilisation rule, which would require that a monetary policy counterparty manages its collateral pool such that it complies with a given "alignment"

\footnotetext{
${ }^{16}$ Note that large amounts of eligible collateral have been excluded from the optimisation problem.
} 
reference value. For the central bank, this approach would be akin to a form of "climate-hedging" against transition risks.

The analysis and the experiment described above shed light on some design questions a central bank would need to address should it consider such an approach.

- Some of them are linked to the current state of development of the methodologies available to assess the "alignment" of financial assets.

- Using one or more methods? As indicated above, several methodologies are currently available. They differ in terms of components, scope and outputs and may not serve the same purpose equally well. As a policy institution whose credibility depends on the robustness and reliability of its tools and assessments, a central bank would need to assess and test thoroughly these methods. To a large extent, this would be similar to what is done for credit rating methodologies, which are screened by central bank experts before being used in the collateral policy. The main and challenging difference is that there is no consensus yet on what should be the core components of a robust "alignment" methodology. Even if that were the case, sound policy design would call, as our experiment suggests, for a central bank to use several methods and metrics simultaneously to design any rule requiring monetary policy counterparties to "align" their collateral pools.

- How stringent? Another design question relates to the level of protection against "misalignment"/transition risks the central bank considers necessary. In practice, answering this question requires us to decide on two issues. One is how stringent the chosen methodologies should be, i.e. how comprehensive the "alignment" measure should be. As indicated already, whether the "alignment" metric is built on Scopes 1 and 2 or also includes Scope 3 GHG emissions data yields very different results for a given asset class. All else being equal, the latter approach is likely to result in more conservative estimates of the "misalignment"/transition risk. Yet, this may come at the cost of increased uncertainty as Scope 3 GHG emissions are more difficult to assess with precision. The second issue concerns the choice of the reference value of the "alignment" metric with which collateral pools would have to comply. One straightforward option would be to choose a value consistent with the Paris Agreement global temperature target $\left(1.5^{\circ} \mathrm{C}\right)$. The rationale for doing so is that the EU has signed the Paris Agreement. Yet, variants could be envisaged, including a gradual tightening of the reference value to allow for a smooth adjustment of counterparties to this new type of requirement.

- How to compute the reference "alignment" value at pool level? In the experiment, the approach has been to measure the "alignment" value of the collateral pool as a weighted average. One motivation for this choice is to keep the approach lean and simple. Yet, this choice has limitations. An important one, from a risk protection perspective as well as from a climate change perspective, is that this 
implicitly assumes that better "aligned" assets can compensate for the transition/"alignment" risks embedded in the worst "aligned" assets. Whether this logic, which is consistent with standard portfolio diversification theory, applies when it comes to climate-related financial risks needs to be confirmed. To circumvent this fundamental issue, an alternative approach might be to draw inspiration from other, less sophisticated, sustainable investment strategies, such as worst in class or best in class strategies.

- Other design questions relate to the scope of asset classes whose "alignment" should be monitored, assessed and ascertained.

- One relates to the breadth of eligible asset classes that should be covered for the protection measure to be relevant. Typically, "alignment" metrics were initially designed for corporate issuers. From a collateral policy perspective, applying them to the corporate debt asset class would be rather straightforward. The experiment above signals, however, that applying "alignment" metrics beyond corporate securities to asset classes such as structured products or sovereign bonds may raise specific challenges. This signals that a central bank would have to assess the policy relevance of covering all or part of its eligible universe.

Besides, from a strictly technical viewpoint, covering eligible assets such as non-marketable assets and ABS (see Appendix C) would raise several methodological challenges and call for additional work. For instance, non-marketable SME loans and transition plan data may not exist, making it particularly difficult to assess their debt from a climate-related risk perspective and the use of sector metrics as proxies inevitable. Similarly, evaluating ABS precisely would require an analysis of the underlying pool of assets as applying the "alignment"/transition risk value of the originator to the structure can only be a rough proxy. For instance, residential mortgages could be assessed based on their energy efficiency rating (if available) and automobile loans could be assessed through the climate performance of the manufacturers.

- A second dimension relates to adequate coverage within a given eligible asset class. Given the breadth of eligible collateral in some central banks and given the current state of development of "alignment" data and methodologies, metrics are not always available for all issuers of a given asset class (for instance, corporate debtors of credit claims may not have an "alignment" rating). From a policy perspective, this situation would require the central bank to decide on how to estimate the missing values (the mean vs the median vs the worst rating, of the whole eligible universe vs a given asset class (e.g. all corporate issuers) vs the economic sector to which the issuer belongs).

Beyond the main design questions listed above, a central bank would also need to pay due attention to the intended and unintended aggregate effects of seeking to "align" its counterparties' pools of eligible assets. In particular, the central bank would need to assess both the static and the dynamic impacts that 
"aligning" collateral pools may have on asset availability, pricing and liquidity. If some assets appear to be "less aligned", they may lose market value and trade at a premium. Conversely, if other assets are "more aligned", counterparties may be tempted to pledge them comparatively more. Depending on the "interest of being eligible", this may result in shifts in relative pricing across assets and, possibly asset classes.

In addition to the market impact, paying attention to the impact at the monetary policy counterparty level would also be in order. Indeed, it is critical from a monetary policy perspective to assess whether all counterparties might be able to adjust the composition of their collateral pools. This would depend on their ability to source "aligned assets" - either in the market or by originating them, domestically or cross-border and, more generally, on their specific business model and the type of assets on their balance sheets. In other words, a more detailed analysis of the actual availability of these assets is necessary.

\section{CONCLUSION}

This paper is a contribution to the ongoing efforts to assess whether central banks could consider adjusting their collateral framework to better account for climate-related financial risks. More specifically, it tests whether so-called "alignment" methodologies and metrics, used as proxies for transition risk, could be useful in capturing their exposure to such risks at the level of the collateral pool of monetary policy counterparties. To do so, this experiment leverages two specific "alignment" methodologies, which are considered here as examples of what could be envisaged.

The case for investigating "alignment" methodologies at the collateral pool level rests on two main arguments. One is that this allows us to design an approach that would comply with the guiding principles that typically underpin a central bank's collateral policy. In particular, the approach adopted in this paper is likely to be consistent with market neutrality, which alleviates an important concern central banks may have when considering climate-related measures. Indeed, in practical terms, the approach leaves full flexibility to counterparties in managing the detailed composition of the collateral pools they pledge to access refinancing operations. From that perspective, it differs from more directly prescriptive options, such as exclusion (worst in class) or preference (best in class) solutions.

The second key consideration supporting the choice made in this paper is that, from a methodological perspective, "alignment" methodologies seem to better address radical uncertainty than alternative approaches such as probability-based climate-related risk metrics (e.g. climate VaR) or approaches relying on climate-economy models. This being said, "alignment" methodologies also involve critical methodological choices in the presence of a high level of complexity and uncertainty, which should lead to interpret the results cautiously. 
The paper tests the compatibility of eligible and pledged collateral with a $1.5^{\circ} \mathrm{C}-2^{\circ} \mathrm{C}$ scenario, according to several "alignment" methodologies and metrics. The numerical experiment using Eurosystem marketable collateral data suggests that, in aggregate, neither the Eurosystem eligible collateral universe nor the collateral pledged with it, is "aligned". This is likely to be a consequence of the breadth of the marketable collateral universe, which mirrors the financing of the real economy. The experiment also suggests that there is heterogeneity in "alignment" and carbon intensity across counterparties' marketable collateral pools. Finally, the experiment also seems to suggest that there may be scope for improving the "alignment" without severely tightening the Eurosystem eligible marketable collateral universe. Yet, the paper does not document whether, in practice, "aligning" counterparties' collateral pools would be consistent with the smooth conduct of monetary policy operations.

The experiment also sheds light on some policy design questions that are relevant for a central bank considering the use of "alignment" metrics for risk monitoring purposes or in collateral mobilisation rules. Quite clearly, embedding climate-related risk metrics implies some degree of operational complexity for central banks, which may be the cost to pay to adjust their collateral policy to climate change. In particular, it implies making important design choices, for which there may not be straightforward answers. That said, further investigations are needed on several policy dimensions. One relates to the ability of counterparties to source, originate and pledge "aligned" collateral pools. Another relates to the market impact across asset classes of "aligning" their collateral pools.

The results presented in this paper need to be complemented in many ways. At a minimum, it would be valuable to run similar experiments using not only other existing "alignment" metrics, but also other climate-related risk metrics in order to provide robust results that could inform decision-making. In particular, while the focus here was on "aligning" pools of collateral, other approaches based on measuring climaterelated risks on an asset-by-asset basis are also relevant from a policy perspective. 


\section{REFERENCES}

Aglietta, M. and Espagne, E. [2016]. "Climate and Finance Systemic Risks, More than an Analogy? The Climate Fragility Hypothesis”, CEPII Working Paper, $\mathrm{n}^{\circ}$ 2016-10.

Allen, T., Dees, S., Boissinot, J., Caicedo Graciano, C. M., Chouard, V., Clerc, L., De Gaye, A., Devulder, A., Diot, S., Lisack, N., Pegoraro, F., Rabate, M., Svartzman, R. and Vernet, L. [2020]. "Climate-Related Scenarios for Financial Stability Assessment: An Application to France", Banque de France Working Paper, $\mathrm{n}^{\circ} 774$.

BAtTen, S., Sowerbutts, R. and TANAKA, M. [2016]. "Let's talk about the weather: the impact of climate change on central banks", Bank of England.

BLACK, F. and SCHOLES, M. [1973]. "The pricing of options and corporate liabilities”, Journal of political economy, Vol. 81 (3): 637-654.

BINDSEIL, U., CORSI, M., SAHEL, B. and VISSER, A. [2017]. "The Eurosystem collateral framework explained", ECB Occasional Paper.

Blood, D. AND LeVinA, I. [2020]. "Measuring Portfolio Alignment. Assessing the position of companies and portfolios on the path to net zero". Portfolio Alignment Team.

Bolton, P., Despres, M., Pereira da Silva, L., Samama, F. and Svartzman, R. [2020a]. "The Green Swan, Central Banking and financial stability in the age of climate change", Bank of International Settlements and Banque de France.

Bolton, P., Despres, M., Pereira Da Silva, L., Samama, F. and Svartzman, R. [2020b]. “'Green Swans': central banks in the age of climate-related risks", Banque de France Bulletin, n $229-8$.

CALDECOTT, B. [2019]. “'Encourages laziness and disincentives ambition': Ben Caldecott shares his thoughts on the EU's green taxonomy”, Responsible Investor, 14 June.

CARNEY, M. [2015]. "Breaking the tragedy at the horizon - climate change and financial stability", Speech at the Lloyd's of London.

CARney, M. [2016]. "Resolving the Climate Paradox", Text of the Arthur Burns Memorial Lecture.

Chenet, H., Ryan-Collins, J. and VAn LerVen, F. [2019]. "Climate-Related Financial Policy in a World of Radical Uncertainty: Towards a Precautionary Approach", UCL Institute for Innovation and Public Purpose, $\mathrm{n}^{\circ} 2019-13$.

Cochran, I. and Pauthier, A. [2019]. "Alignment with the Paris Agreement: Why, What and How for Financial Institutions?”, Institute for Climate Economics.

COEuRÉ, B. [2018]. "Monetary Policy and Climate Change", Speech at a conference on "Scaling up Green Finance: The Role of Central Banks", organised by the Network for Greening the Financial System, the Deutsche Bundesbank and the Council on Economic Policies, Berlin, 8 November 2018.

EUROPEAN COMMISSION [2020]. "Committing to climate-neutrality by 2050: Commission proposes European Climate Law and consults on the European Climate Pact". Press release by the European Commission, 4 March.

GuÉRet, A., Malliet, P., SAussay, A. and Timbeau, X. [2018]. "An explorative evaluation of the climate debt", OFCE Policy briefs. 
Hepburn, C., SteRn, N. and Stiglitz, J. [2020]. “Carbon Pricing”, European Economic Review.

IAIS (International Association of Insurance Supervisors). [2018]. "Issues Paper on Climate Change Risks to the Insurance Sector", International Association of Insurance Supervisors, Bank for International Settlements.

IPCC. [2014]. "Climate Change 2014: Synthesis Report. Contribution of Working Groups I, II and III to the Fifth Assessment Report of the Intergovernmental Panel on Climate Change”, IPCC.

IPCC. [2018]. "Summary for Policymakers. In: Global Warming of $1.5^{\circ} \mathrm{C}$. An IPCC Special Report on the Impacts of Global Warming of $1.5^{\circ} \mathrm{C}$ above Pre-Industrial Levels and Related Global Greenhouse Gas Emission Pathways, in the Context of Strengthening the Global Response To the Threat of Climate Change", IPCC.

IRENA. [2019]. “A New World - The Geopolitics of the Energy Transformation”, IRENA.

Jourdan, S. and KALINOWSKI, W. [2019]. “Aligning Monetary Policy with the EU's Climate Targets”, Veblen Institute for Economic Reforms \& Positive Money Europe.

KeEn, S., AyRES, R.U. AND StANDish, R. [2019]. “A Note on the Role of Energy in Production”, Ecological Economics, Vol. 157: 40-46.

KeYnES, J. M. [1936]. The General Theory of Employment, Interest and Money. Cambridge: Cambridge University Press.

KING, M. [2017]. The End of Alchemy: Money, Banking and the Future of the Global Economy. New York: W.W. Norton \& Company.

KNIGHT, F. H. [1921]. "Risk, Uncertainty and Profit”, University of Illinois at Urbana-Champaign's Academy for Entrepreneurial Leadership Historical Research Reference in Entrepreneurship.

Krogstrup, S. AND OMAn, W. [2019]. "Macroeconomic and Financial Policies for Climate Change Mitigation: A Review of the Literature", IMF Working Paper, Vol. 19 ( $\left.{ }^{\circ} 185\right)$.

Lenton, T. M., Rockström, J., Gaffney, O., RAhmstorf, S., Richardson, K., StefFen, W. and SCHEllnhuBER, H.J. [2019]. "Climate Tipping Points — Too Risky to Bet Against", Nature, Vol. 575: 59295.

Maier, H. R., Guillaume, J. H.A., van Delden, H., Riddell, G. A., HaAsnoot, M. and KwakKel, J. H. [2016]. "An Uncertain Future, Deep Uncertainty, Scenarios, Robustness and Adaptation: How Do They Fit Together?" Environmental Modelling and Software, Vol. 81: 154-64.

MALKIEL, B. G. and FAMA, E. F. [1970]. "Efficient capital markets: A review of theory and empirical work", The journal of Finance, Vol. 25 (n²): 383-417.

Mazzucato, M. [2015]. The Entrepreneurial State: Debunking Public vs. Private Myths in Risk and Innovation. New York: Public Affairs.

McGlade, C. AND EKINS, P. [2015]. "The Geographical Distribution of Fossil Fuels Unused When Limiting Global Warming to $2^{\circ} \mathrm{C} "$, Nature, Vol. 517 (n 7533$)$ : 187-90.

Merton, R. C. [1974] "On the pricing of corporate debt: The risk structure of interest rates", The journal of Finance, Vol. 19 (n²): 449-470.

Moriarty, P. And Honnery, D. [2016]. "Can Renewable Energy Power the Future?”, Energy Policy, Vol. 93: 3-7. 
NGFS [2018]. "NGFS First Progress Report”, NGFS.

NGFS [2019a]. "NGFS First Comprehensive Report. A Call for Action - Climate Change as a Source of Financial Risk", NGFS.

NGFS [2019b]. "Macroeconomic and Financial Stability: Implications of Climate Change. NGFS Technical Supplement to the First Comprehensive Report", NGFS.

NGFS [2020a]. "NGFS climate scenarios for central banks and supervisors", NGFS.

NGFS [2020b]. “Overview of Environmental Risk Analysis by Financial Institutions”, NGFS.

Raynaud, J., Voisin, S., TAnkov, P., Hilke, A. and PAuthier, A. "The Alignment Cookbook : A Technical Review of Methodologies Assessing a Portfolio's Alignment with Low-Carbon Trajectories or Temperature Goal”, Institut Louis Bachelier.

RegelinK, M., Reinders H. J., Vleeschhouwer, M. and VAN DE Wiel, I. [2017]. "Waterproof? An Exploration of Climate-Related Risks for the Dutch Financial Sector", De Nederlandsche Bank.

RipPle, W., Wolf, C., Newsome, T., BArnard, P., MoOMAW, W. and Gutiérrez CÁrdenas, P. D. A. [2020]. "World scientists' warning on climate emergency", BioScience, Vol. 70: 8-12.

RosE, A. [2014]. La comptabilité des émissions de gaz à effet de serre par enjeu: un outil d'analyse des impacts $d u$ changement climatique sur les activités d'une banque de financement et d'investissement, $\mathrm{PhD}$ Thesis in Economic Science, Paris 9.

SCHNABEL, I. [2020]. "When markets fail - the need for collective action in tackling climate change". Speech at the European Sustainable Finance Summit, Frankfurt am Main, 28 September.

SchoenmakeR, D. [2019]. “Greening Monetary Policy”, Bruegel Working Paper.

StefFen, W., Rockström, J., Richardson, K., Lenton, T. M., FolKe, C., Liverman, D., Summerhayes, C. P. et al. [2018]. "Trajectories of the Earth System in the Anthropocene." Proceedings of the National Academy of Sciences of the United States of America, Vol. 115 ( $\left.\mathrm{n}^{\circ} 33\right)$ : 8252-59.

TCFD [2017]. "The Use of Scenario Analysis in Disclosure of Climate-Related Risks and Opportunities Technical Supplement - Technical Supplement”, TCFD (Task Force on Climate-related Financial Disclosures).

THE SHIFT PROJECT, AND IFPEN. [2019]. "Comprendre Les Enjeux de La Modélisation Du Lien Complexe Entre Énergie, Climat et Économie - Etat Des Lieux et Limites de La Modélisation Énergie-Climat-Économie Au Niveau Mondial", The Shift Project.

VAN “T KLOOSTER, J. AND VAN TILBURG, R. [2020]. "Targeting a sustainable recovery with Green TLTROs”. Positive Money and Sustainable Finance Lab (September).

Vermeulen, R., Schets E., Lohuis, M., KöLbl, B., JANSEN D. J., and HeERINGA, W. [2019.] "The Heat Is on: A Framework Measuring Financial Stress under Disruptive Energy Transition Scenarios." De Nederlandsche Bank Working Paper, $\mathrm{n}^{\circ} 625$.

Villeroy de Galhau, F. [2019]. "Climate Change: Central Banks Are Taking Action”, Banque de France Financial Stability Review, n 23: 7-16.

WeITZMAN, M. L. [2011]. "Fat-Tailed Uncertainty in the Economics of Catastrophic Climate Change", Review of Environmental Economics and Policy, Vol. 5 (n ${ }^{\circ}$ ): 275-92. 


\section{Appendices}

\section{Appendix A - Overview of portfolio "alignment" methodologies}

In recent years, the term "alignment" has emerged and has been developing in the field of portfolio climate analysis. "Alignment" refers to the Paris Agreement of 2015 and the question of "aligning" qualitatively and quantitatively - the investment strategies of public and private financial players with the ambition, enshrined in this international agreement, of keeping the rise in global temperatures to well below $2^{\circ} \mathrm{C}$ by 2100 . Thus, this notion is recent and has developed in a universe of practitioners: climate analysis providers, whether private or NGO, and their clients. To our knowledge, this concept has not yet received a great deal of attention in the academic literature, which may explain the undefined nature of this concept and the diversity of the associated methodologies. The publication of the Institute for Climate Economics (Cochran and Pauthier, 2019) stands out as an exception; it provides financial actors a theoretical framework to "align" their strategies and operations with the Paris Agreement. This comprehensive framework places the notions of impact and contribution to the low-carbon transition at the heart of the concept of "alignment". In practice, impact measurement is difficult to address and most carbon data providers do not dwell on the impact side when they talk about portfolio "alignment". Rather, the "alignment" methodologies developed by these climate analysis providers consist in comparing the GHG emissions or technological trajectories of the companies with reference trajectories for a smooth low-carbon transition. This benchmark introduces a normative aspect to the analysis, which otherwise relies mainly on descriptive data. As regards the notion of "portfolio temperature", it arises when investors aim to quantify the extent to which their portfolios are "aligned" or "misaligned" with the reference transition pathway: it measures a distance to the climate benchmark. It would probably be an overstatement to say that "alignment" tools provide a measure of the impact of an investment strategy. Nor are they tools for calculating financial risks in monetary terms. However, they provide interesting metrics to evaluate, at an aggregate level, to what extent a portfolio may be affected by transition shocks.

We now turn to the main components - data sources and methodological principles - of the "alignment" tools. This list is not necessarily exhaustive, nor do the elements presented here necessarily appear in all methodologies, but it provides a general insight as to what the "alignment" tools are. For a comprehensive review of "alignment" methods, see Raynaud et al., 2020.

\section{i. Data sources}

The "alignment" methodologies exploit granular information about the companies they analyse, which are essentially large and mid-cap companies. The first type of information used by the "alignment" methodologies is companies' historical and present GHG emissions inventory data. The GHG accounting 
standards (e.g. GHG Protocol, ISO 14064, Bilan Carbone ${ }^{\circledR}$, etc.) cover six greenhouse gases and are structured in three scopes:

- Scope 1 corresponds to the company's direct emissions, i.e. emissions due to combustion and leaks within its area of responsibility;

- Scope 2 corresponds to emissions induced by the production of the energy purchased by the company;

- Scope 3 corresponds to all remaining indirect GHG emissions in the value chain, upstream and downstream, including the use and end-of-life of products sold.

The vast majority of large companies that have completed inventories of their GHG emissions report this to the NGO CDP, which probably has the largest database of this kind in the world. We underline that this data is declarative and that the inventory process and its auditability are subject to very few audit requirements. As a result, some "alignment" providers assess the reliability of this information by cross-checking it with data that underpins a company's emissions (sectoral information, revenues, etc.). In addition to companies' actual emissions, the emission targets that companies set for themselves are another source of data used by "alignment" analysis providers. Some of them also use asset-level databases: such databases reference factories, power plants, mines, and other facilities around the world and link them to companies. This database inventories the facilities but also their historical and forecasted production levels as well as investment plans. This data is valuable for comparing companies' official GHG targets and their likely evolution. Finally, public financial, extra-financial and strategic reporting from large companies to investors is also a source of information exploited by the "alignment" methodologies, as well as other communication channels such as websites.

"Alignment" methods use not only internal company data, but also external data. This mainly concerns techno-economic scenarios, against which corporations' "alignment" is measured. The need for scenarios stems from the fact that, apart from a temperature target, the Paris Agreement does not provide very detailed targets for GHG emissions. ${ }^{17}$ The purpose of using a scenario is to translate a temperature objective into sector-by-sector emissions trajectories. The scenarios also provide reference trajectories for sectoral carbon intensities (e.g. what should be the average emissions associated with the production of $1 \mathrm{kWh}$ of electricity in 2025?) and for technological choices (e.g. what should be the proportion of renewables in the world electricity mix in 2025?). These scenarios play a central role in most of the "alignment" methodologies: they ground the normative dimension of the "alignment" analysis. Their choice is not fully neutral because these scenarios depend on certain assumptions about how to implement the transition. How to share efforts

\footnotetext{
${ }^{17}$ Many states have committed to respecting carbon budgets (Intended Nationally Determined Contributions) but these emission targets are globally not consistent with the $2^{\circ} \mathrm{C}$ objective (UNFCCC, 2016).
} 
between sectors? Between countries? Should we bet on a backstop technology? The dominant scenarios today, most used by the "alignment" analysis providers, are the IEA's World Energy Outlook and Energy Technology Perspectives. However, there are calls for the use of alternative scenarios, offering another perspective on how the transition should be. Moreover, some methodologies propose multiple scenarios or rely only partially on them.

\section{ii. Methodological principles}

The first major methodological topic concerns the estimation of GHG emissions data, for companies that do not report their emissions, or only on a limited scope. The service providers use regression models to deduce the unknown data, based on the sector and many activity metrics, but also to check the reliability of the companies' disclosure. The providers keep such models confidential, as they constitute the core of their analysis process and thus a competitive advantage. Some providers like S\&P Trucost prefer to exclude companies with estimated GHG emissions: they provide this estimation but do not use it to judge the company's "alignment". In such a case, some providers also have a conservative approach: the lack of reporting is a sign of "non-alignment". Another methodological topic is the issue of allocating a GHG emission budget to micro-entities based on macro- or sectoral-transition scenarios. How to break down a global GHG budget into an entity-level budget? Which objective criteria should we use to decide such an allocation? For this task, several "alignment" analysis providers use the Science Based Target Initiative (SBTI) methodologies, which use - among others - the forecasted growth of the company to assign a carbon budget. The last major methodological issue we identified concerns the attribution of economic activities and the corresponding externalities to financial assets. Indeed, this question arises when considering the carbon footprint of a portfolio and its "alignment". It also determines how one aggregates the climate scores of the different assets in the portfolio and thus how they compensate each other. For GHG emissions, the most common approach is to allocate a company's GHG emissions to an investor - or a creditor - in proportion to the investor's share in the company's liabilities: if an investor holds $1 \%$ of a company's liabilities, it is assigned $1 \%$ of the company's emissions. For carbon intensity metrics or qualitative scores, the preferred approach is, in most cases, a socalled "portfolio" approach: the portfolio score is the average score, weighted by the share of each asset in the portfolio. 


\section{APPENDIX B - THREE MAIN TYPES OF “ALIGNMENT” METRICS}

1. Emission gap. The first possible metric is the company's GHG emissions expected under or over a $2^{\circ} \mathrm{C}$ carbon budget over a given time period. Here the notion of budget refers to the second methodological principle previously mentioned: according to a specific $2^{\circ} \mathrm{C}$ scenario and following certain predefined and objective allocation rules, a certain carbon budget can be allotted to each company for a given period. This metric may be handled in absolute value (overshoot in tCO2e) or in relative value (overshoot in \%). S\&P Trucost achieves this approach for instance.

2. Output and technological metrics. Another option is not to use GHG emissions as the basis for determining a company's "alignment", but to use indicators of economic activity or technological choices. For a company engaged in the extraction of fossil fuels, for example, one can examine the forecasted coal production (in absolute terms) for the coming years and compare it with the rate of evolution of coal production in a $2^{\circ} \mathrm{C}$ transition scenario. For an electric power company, one can look at its production mix; for a car manufacturer, one can look at the share of electric cars sold and compare it with the share in the transition scenario. The $2^{\circ}$ Investing Initiative (2DII) applies this approach, focusing on seven high-stakes sectors.

3. Overall rating based on a multi-criteria approach. Some providers, such as Carbon4 Finance, take a multi-criteria approach based on the premise that a single raw metric such as absolute GHG emissions is not sufficient to determine a company's "alignment". A multi-criteria approach enables one to mix the carbon footprint information with more sector-specific criteria (carbon intensity of processes, R\&D investments, avoided downstream emissions, etc.) or with expert analysis on the company strategy. A transparent analysis grid can nevertheless objectify this qualitative aspect based on expert opinion. The advantage of a global rating - which merges the different dimensions of the analysis - is that it makes possible the comparison and the aggregation of the scores of companies in different sectors. However, such an approach requires an ad hoc calibration step to convert this global score into a portfolio temperature.

Another category of methods, such as those performed by CDP Tropic, Ecoact or Rights.based, is based on the GHG emission reduction targets that companies set for themselves. 


\section{APPENDIX C - METHODOLOGICAL CHALLENGES RELATED TO THE COVERAGE OF ASSETS PLEDGED AS COLLATERAL}

Two general types of assets are not easily compatible with existing "alignment" methodologies. First, assets issued by entities that cannot be treated as non-financial corporations. It arises for assets issued by:

- Credit institutions or other financial corporations. There are different approaches on the subject of credit institutions. The main question is whether the climate analysis should only focus on the institution itself, as we would treat any office business, or should also include a climate analysis of the activities financed by the institution. For the analysis we conduct, it seems clear that we are not only interested in knowing whether a particular bank is optimising the energy consumption of its servers or promoting teleworking. A bank's resilience to the low-carbon transition depends very much on its financing and investment strategy. The comprehensive scope that we chose was corroborated by the inclusion of the financed emissions in GHG accounting standards such as the GHG protocol or the French Bilan Carbone ${ }^{\circledR}$. It also ties into the theoretical framework for "alignment" proposed by Cochran and Pauthier (2019), who recommend a comprehensive scope of analysis. As regards financial corporations other than credit institutions, there are two possible cases: either they belong to an industrial group and are therefore attached to its holding company, or they are treated as a purely financial institution.

- National and supranational agencies. Public credit institutions are analysed like any financial institution.

- National governments. As for financial institutions, analysing national governments raises the question as to whether we should include only the direct emissions of public services or if we should adopt a broader scope. On this subject, the data providers are quite "aligned": their analyses also include the carbon intensity of their country's economy. Some providers also take into account the climate policy choices and declared ambition, for instance the gap between their Intended Nationally Determined Contribution (INDC) and their theoretical $2^{\circ} \mathrm{C}$ carbon budget. The important question is why a metric like carbon intensity is interesting for a matter of long-term risk portfolio assessment. In an area such as the EU, where the need for a transition is a consensus, a country's carbon intensity represents a certain overall abatement cost for its economy ${ }^{18}$ and it may be partly borne by public finances, directly or indirectly. An open question is whether this national GHG emissions inventory should also include imported emissions, which also represent a carbon dependency and a risk of increased import costs for an economy.

\footnotetext{
${ }^{18}$ Some authors even speak of climate debt (Guéret et al., 2018), to describe the net present value of a flow of investment needed under a scenario, where you choose to respect commitments.
} 
- Local governments. Some providers, such as Carbon4 Finance, also include certain local governments in their analysis in an analogous manner to national governments. The main entities in terms of eligible asset issuance are covered, but many local governments issuing bonds are not included in the databases of carbon data providers.

Second, some assets (re)financing entities are not clearly identifiable or are too small to be included in the carbon databases of the providers. The matter here is not the nature of the issuer (or debtor) but the ability to identify it and have precise data on it. This issue arises for the following eligible assets classes:

- Non-marketable assets as credit claims. The issue with credit claims (non-marketable assets) pledged as collateral is that many debtors are micro-debtors. For instance, they could be any SME or hospital. Hence, a significant part of these debtors is not included in the carbon databases. For some metrics like carbon intensity (per euro of revenue or per euro of liability) it is possible to use national sectoral averages to characterise each credit claim whose debtor's carbon intensity is not precisely known, in the manner of the P9XCA methodology (Rose, 2014). However, the results presented in this study do not cover non-marketable assets.

- Asset-backed securities (ABS): an ABS is a security whose income payments are derived from a specified pool of underlying assets such as residential mortgages or public sector or auto loans. The ABS is a debt security issued by a Special Purpose Vehicle (SPV) that holds the underlying assets: to that extent, the ABS refinances the underlying assets. Therefore, from a climate analysis perspective, assessing the ABS means assessing the underlying assets. With the evolution of regulations on the disclosure of information, more and more data on the debtors of underlying assets is accessible for authorities. However, this data is rarely climate specific and the debtors, micro-debtors included, are not covered by the carbon databases. As for credit claims, it may be possible to treat the underlying assets with a sectoral approach, but we decided to exclude them from a first analysis.

- Covered bonds. These assets are bonds issued by credit institutions and collateralised by credit claims like residential-mortgage or public sector loans. Like an ABS, a covered bond is a security refinancing a pool of non-marketable assets. However, there are technical and legal distinctions between ABS and covered bonds. From a technical point of view, it is difficult to access the data of the underlying asset. From a legal and accounting point of view, the covered bond and the asset collateralising it still, in most cases, appear on the balance sheet of the credit institution that originated them, contrary to the case of ABS. For these reasons, we chose to include covered bonds in our analysis, treating them as uncovered bank securities. It is consistent with the idea that the "alignment" of a bank group is measured depending on what it finances. 
Appendix D. Temporal statistics

i. Credit institutions
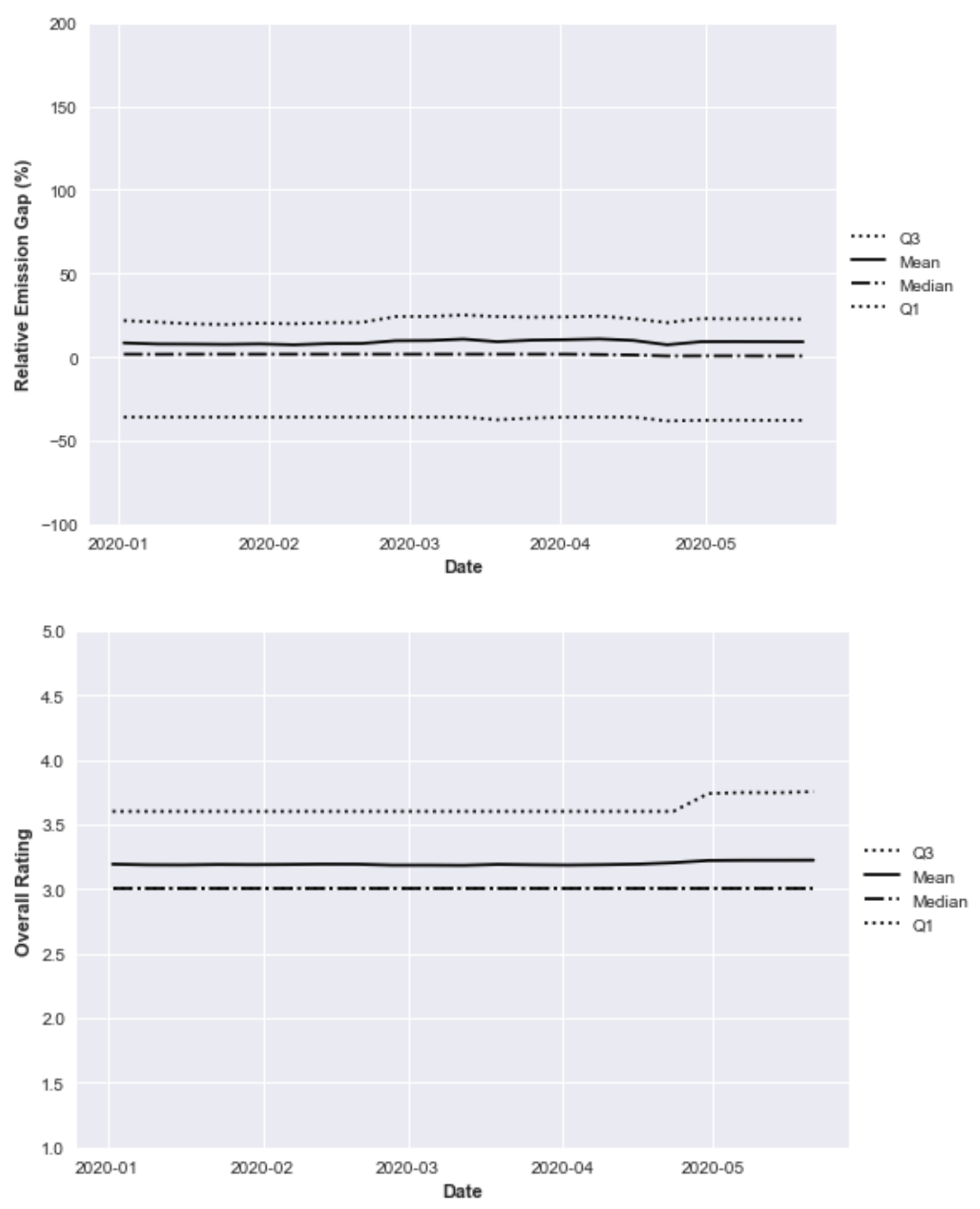

ii. Non-financial corporations 

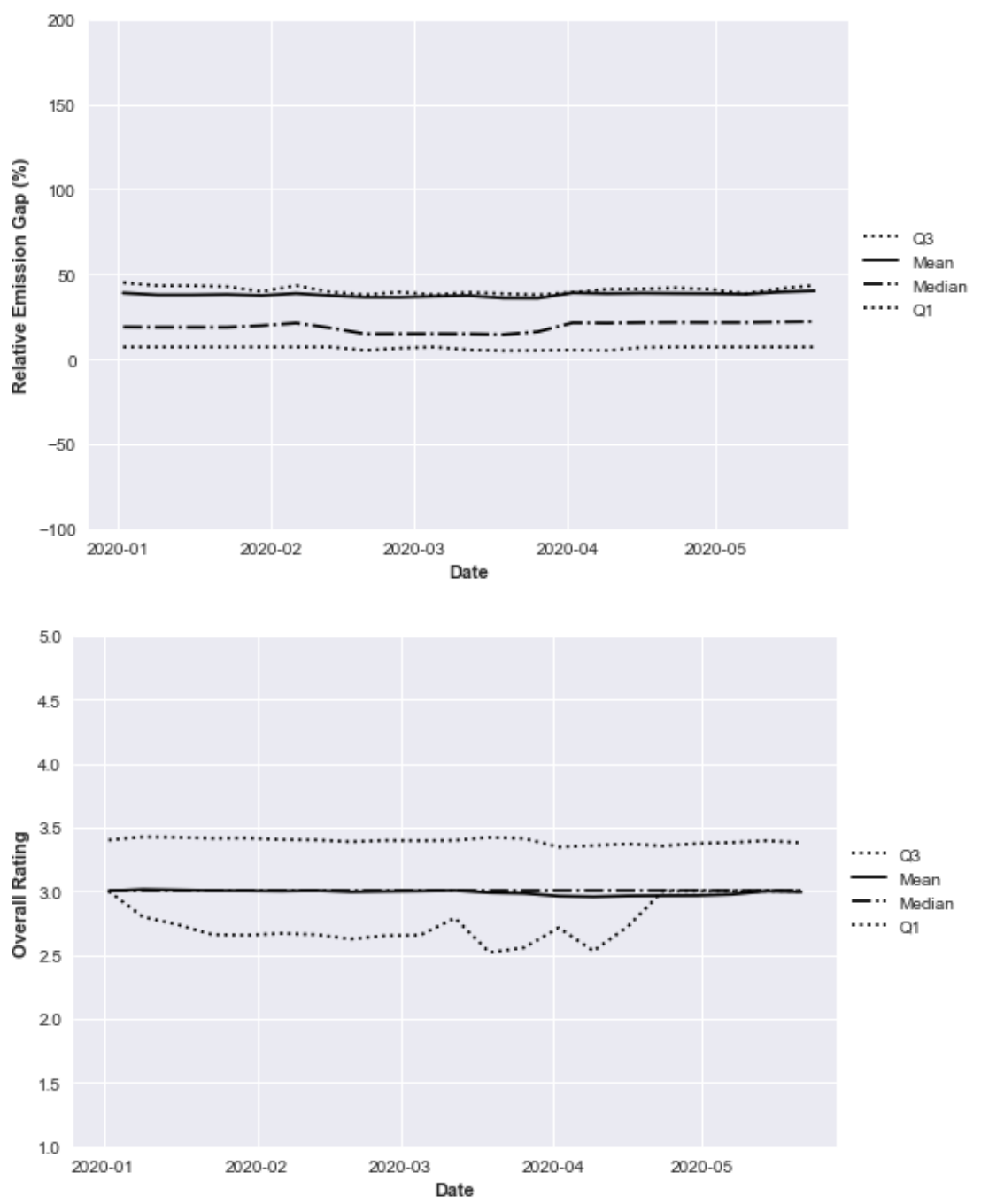

iii. Financial corporations

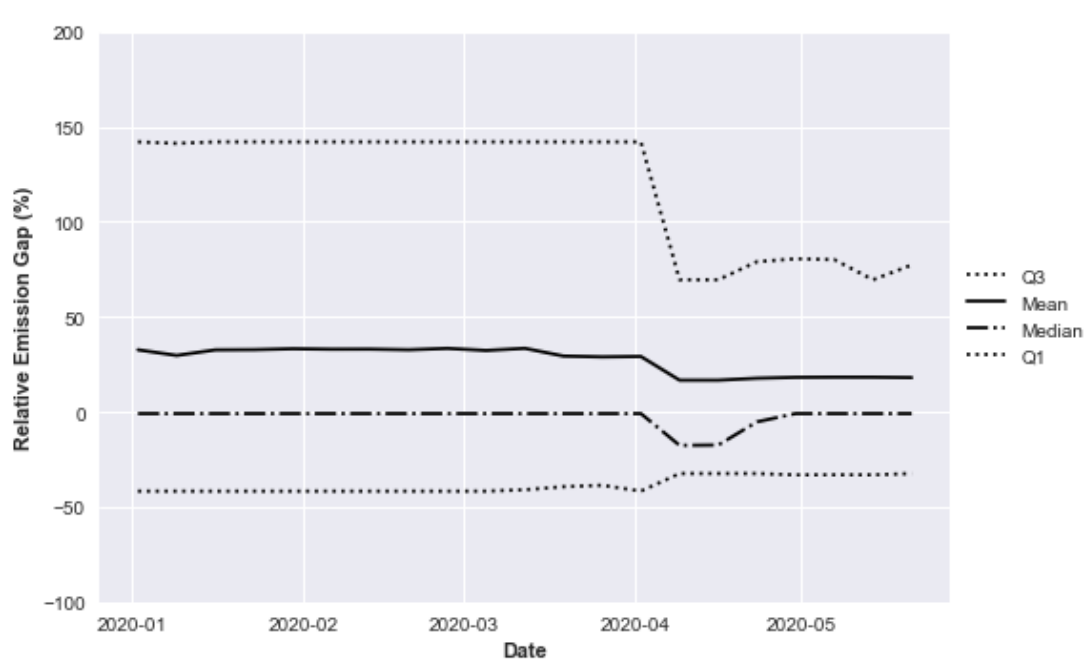




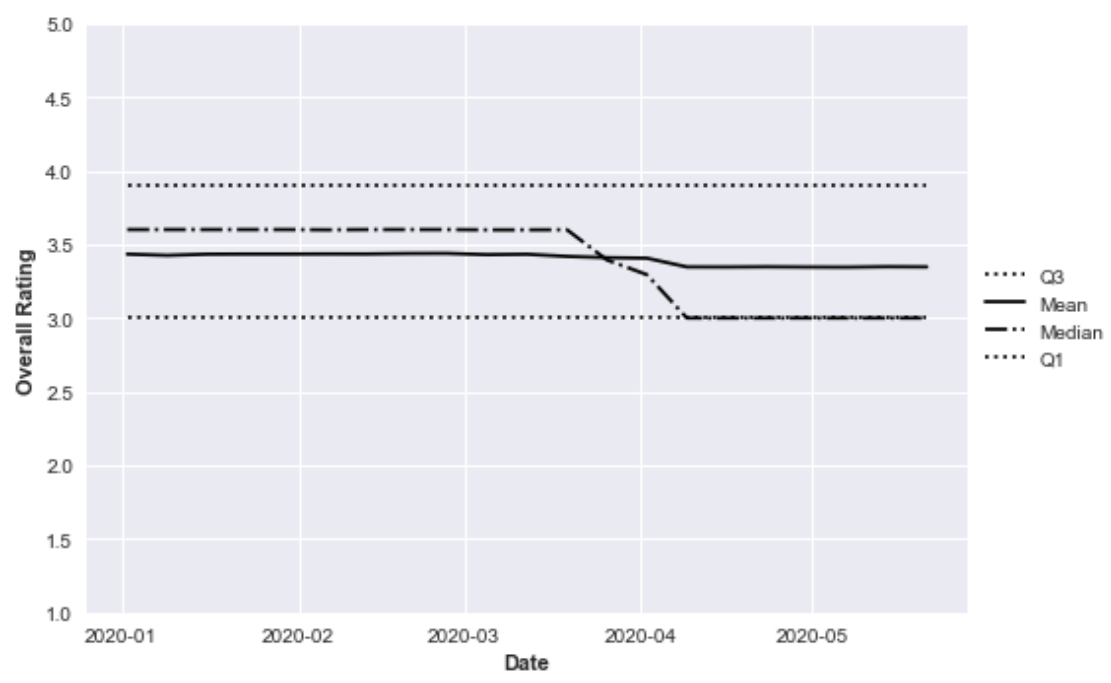

iv. Central governments

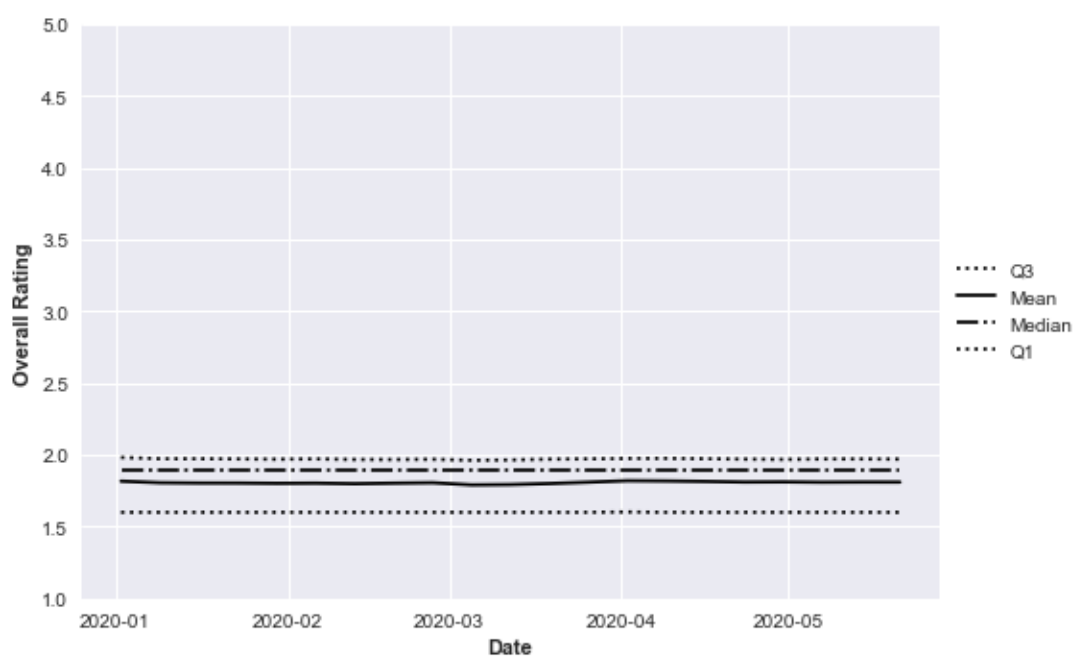


Appendix E. Comparison of eligible and pledged collateral i. Credit institutions
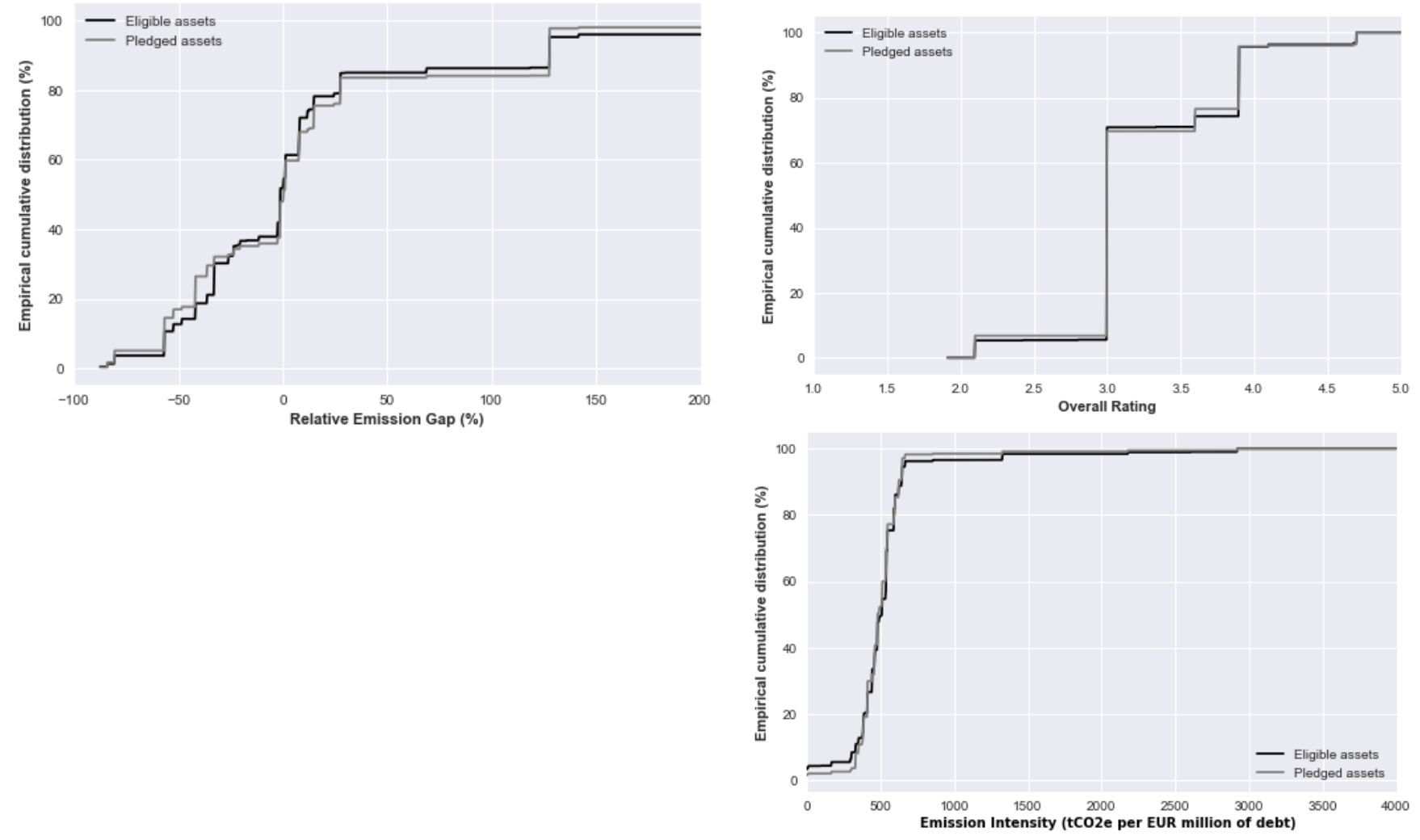

ii. Non-financial corporations
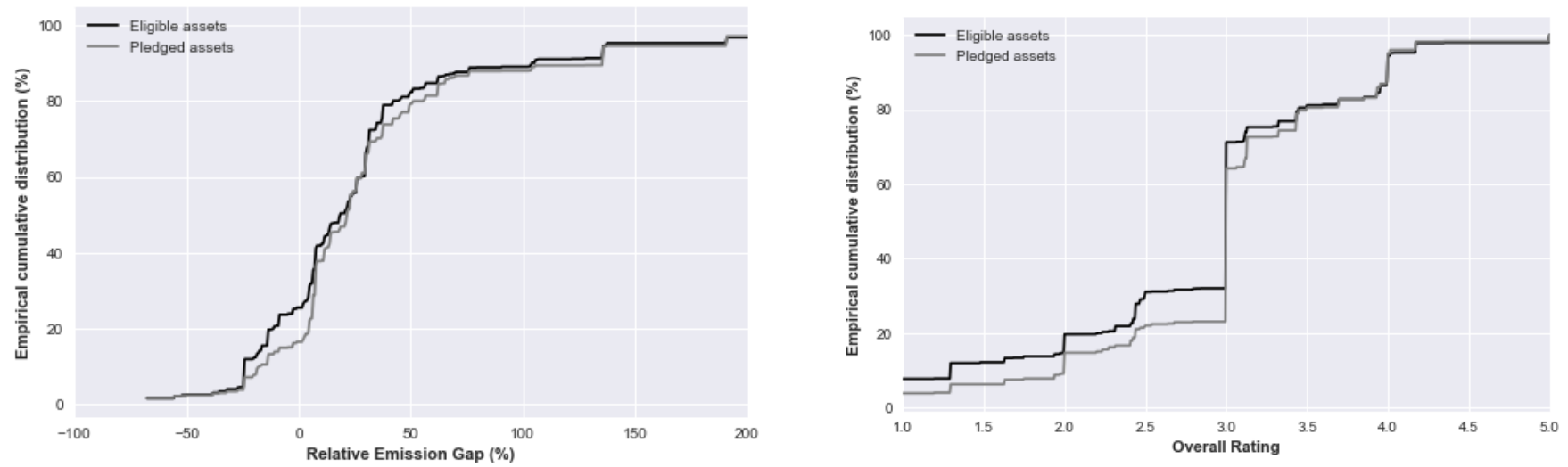


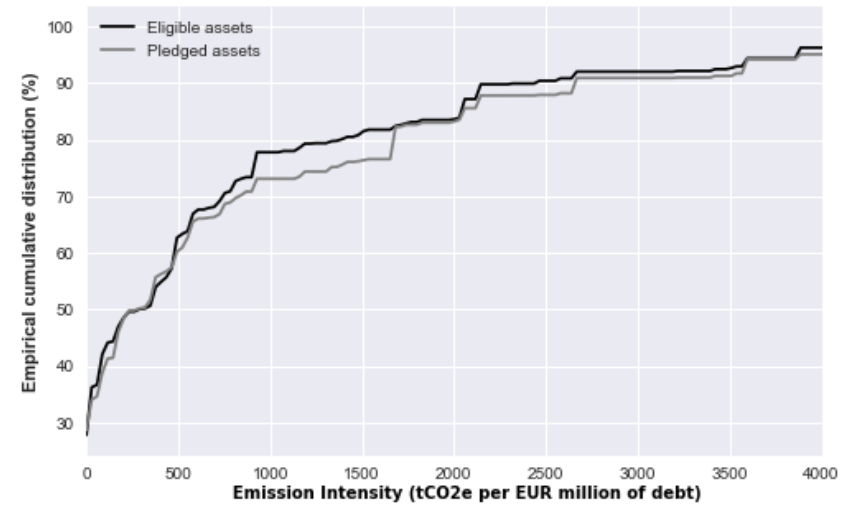

iii. Financial corporations
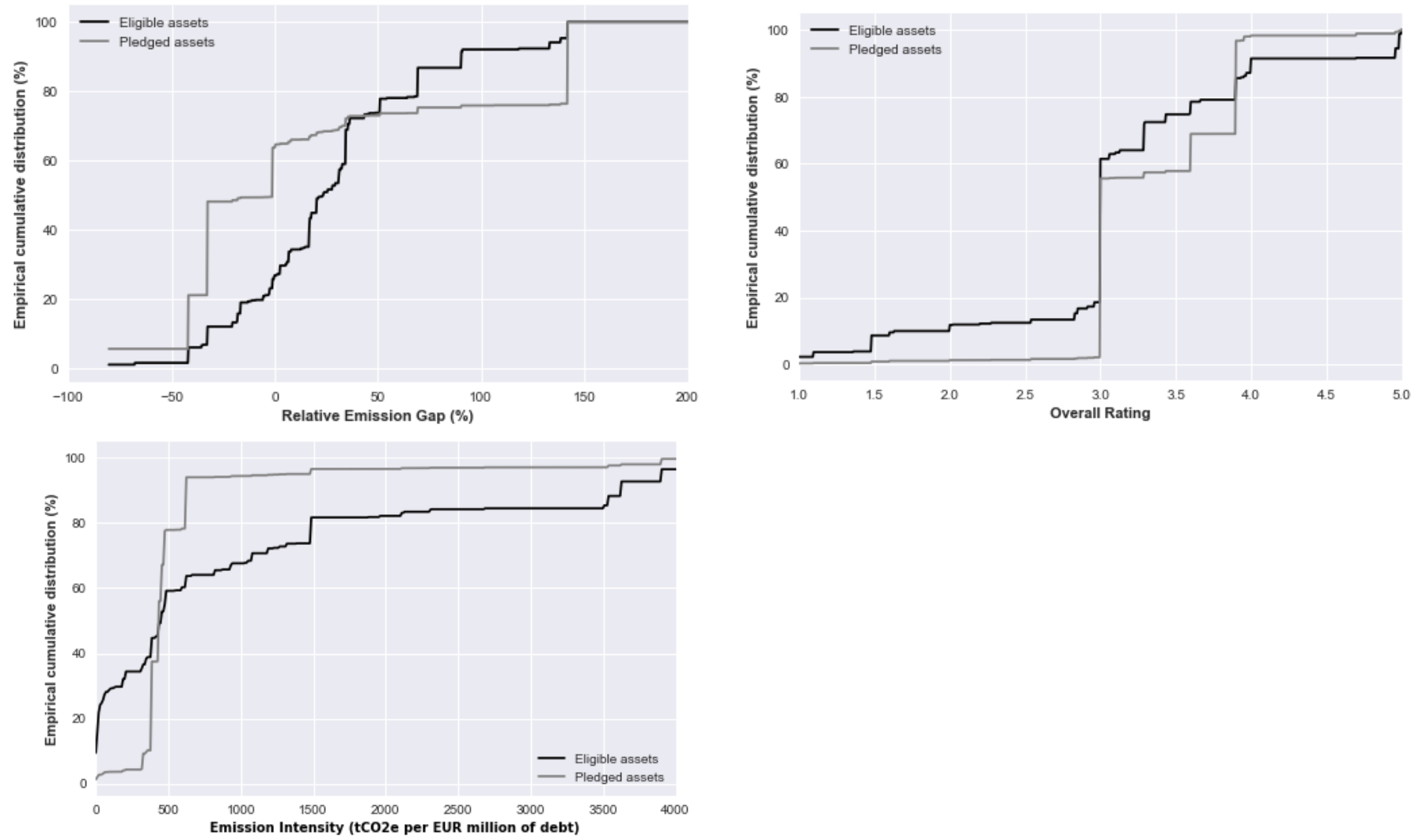

iv. Central governments
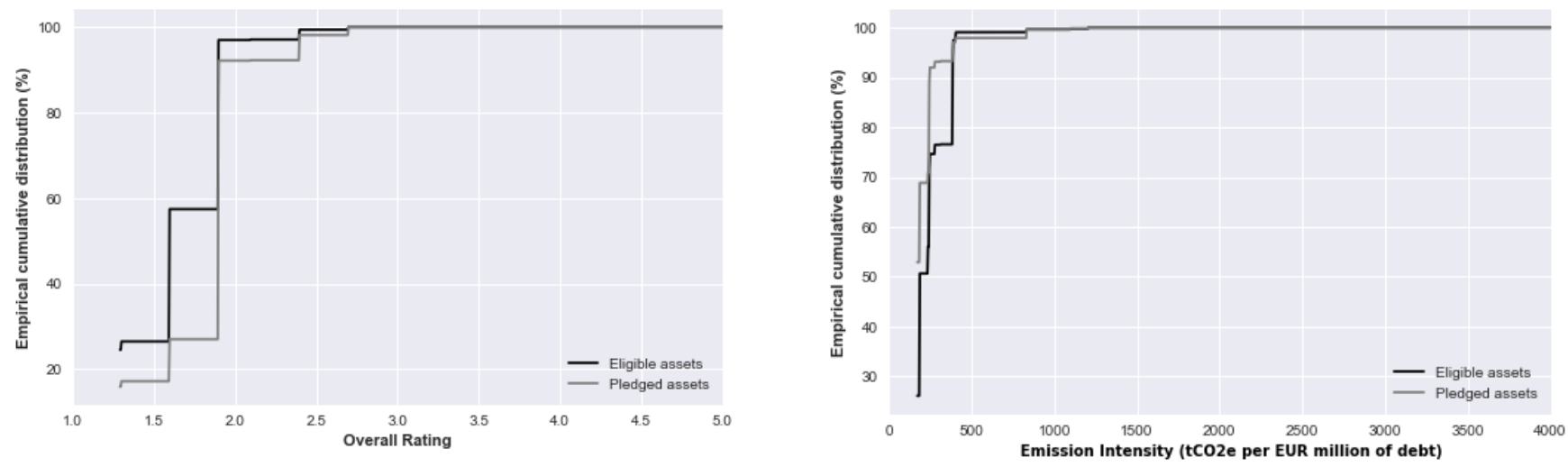


\section{Appendix F-Optimisation problem}

We consider the maximum amount of eligible securities outstanding that can be considered ${ }^{\prime \prime} \mathrm{x}^{\circ} \mathrm{C}$ aligned". More specifically, for one criterion $e$ and an associated target level $e^{\prime}$, what is the maximum amount of eligible securities meeting this target level on average? We provide a preliminary answer to this question by focusing on the following three types of security issuers: financial corporations, non-financial corporations and credit institutions. We chose not to include sovereign securities in order to compare the curves obtained for the S\&P Trucost and Carbon4 Finance criteria. To answer this question, we also need to explain how we deal with issuers that are not included in the S\&P Trucost and Carbon4 Finance databases made available to us. We make the following assumption: for the criteria considered, the issuers not covered follow the same distribution as the covered issuers. This assumption is a simplification, but it is a reasonable starting point, as it is not clear whether non-covered issuers tend to be better or worse rated than the others. Thus, we assign random ratings to non-covered securities based on the distribution of ratings within their issuer category. Since we are not interested in the "micro" results of this calculation but only in an aggregate amount, the form of the score distribution matters. For the issuer category of index $j$, we denote by $A_{j}$ the set of eligible assets issued by such entities and $p_{j}$ the current proportion of this category among the pledged collateral. We are seeking to obtain an upper bound on the size of an "aligned" collateral reservoir, but without this "alignment" leading to too great a shift in the proportions of the pledged asset classes. To do so, we introduce a slackness parameter $\delta$ and we impose minimum and maximum proportions $p_{j}^{\min }=\max \left(0, p_{j}-\delta\right)$ and $p_{j}^{\max }=\min \left(1, p_{j}+\delta\right)$ for each of the three categories of issuers studied here. The optimisation problem that we solve for a given value of $e^{\prime}$, is

$$
\begin{array}{cl}
\max _{q \in \mathbb{R}_{+}^{\mathcal{A}}} & \sum_{i \in \mathcal{A}} q_{i} \\
\text { s.t. } & \sum_{i \in \mathcal{A}} e_{i} q_{i} \leq \bar{e} \sum_{i \in \mathcal{A}} q_{i} \\
& Q_{i} \geq q_{i}, \forall i \in \mathcal{A} \\
& p_{j}^{\min } \sum_{i \in \mathcal{A}} q_{i} \leq \sum_{i \in \mathcal{A}_{j}} q_{i} \leq p_{j}^{\max } \sum_{i \in \mathcal{A}} q_{i}, \quad \forall j \in\{1,2,3\}
\end{array}
$$

where $Q_{i}$ represents the eligible outstanding amount of asset $i$. This problem is a linear programming problem with a few thousand variables that we solve with the open source Scipy library. In the charts presented, the greyscale curves represent the value of the problem as a function of parameter $e^{\prime}$, for three values of $\delta=5 \%, 10 \%, 20 \%$ and for different random draws of the scores of issuers that are not included in the carbon databases at our disposal. 